\title{
Review of On-Scene Management of Mass-Casualty Attacks
}

\author{
Annelie Holgersson
}

Department of Surgical and Perioperative Sciences, Division of Surgery, Center for Disaster Medicine, Umeå University, Umeå, Sweden. E-Mail: annelie.holgersson@umu.se; Tel.: +46 702171695

Submitted: 27 January 2016 | In revised form: 8 June 2016 | Accepted: 8 July 2016 |

Published: 29 August 2016

\begin{abstract}
Background: The scene of a mass-casualty attack (MCA) entails a crime scene, a hazardous space and a great number of people needing medical assistance. Public transportation has been the target of such attacks and involves a high probability of generating mass casualties. The aim of the review was to investigate challenges for on-scene responses to MCAs and suggestions made to counter these challenges, with special attention given to attacks on public transportation and associated terminals. Methods: Articles were found through PubMed and Scopus, "relevant articles" as defined by the databases, and a manual search of references. Inclusion criteria were that the article referred to attack(s) and/or a public transportation-related incident and issues concerning formal on-scene response. An appraisal of the articles' scientific quality was conducted based on an evidence hierarchy model developed for the study. Results: One hundred and five articles were reviewed. Challenges for command and coordination on scene included establishing leadership, inter-agency collaboration, multiple incident sites, and logistics. Safety issues entailed knowledge and use of personal protective equipment, risk awareness and expectations, dynamic risk assessment, cordons, defensive versus offensive approaches, and joining forces. Communication concerns were equipment shortfalls, dialoguing and providing information. Assessment problems were scene layout and interpreting environmental indicators as well as understanding setting-driven needs for specialist skills and resources. Triage and treatment difficulties included differing triage systems, directing casualties, uncommon injuries, field hospitals, level of care and providing psychological and pediatric care. Transportation hardships included scene access, distance to hospitals, and distribution of casualties. Conclusion: Commonly encountered challenges during unintentional incidents were augmented during MCAs, implying specific issues for safety, assessment, triage, and treatment, which require training. Effectively increasing readiness for MCAs will likely entail struggles to overcome fragmentation between the emergency services and the broader crisis management system as well as enabling critical and prestige-less, context-based assessments, of needed preparatory efforts.
\end{abstract}

Keywords: antagonism; disaster response; emergency medical services; fire fighter; law enforcement; mass transportation; mass-casualty incident; rescue work; terrorism

\section{Introduction}

The scene of an antagonistically induced mass-casualty incident, also called mass-casualty attack (MCA) [1], entails a crime scene, a hazardous space, and medical challenge, demanding a complex response by the police, rescue services and emergency medical services (EMS). Countering the aspects, with overlaying short- and long-term priorities and differing organizational roles, is key to optimal functioning in the response stage of an event. This includes early 
planning for transfer of response organizations to the scene of the attack, prevention of disturbances and additional attacks, and prompt and efficient care of the victims [2]. It also implies a need to take care so that the initial rescue priorities do not unnecessarily impact long-term priorities, such as careless handling of bodies which could reduce the possibility of identification [3]. Response to an MCA thus creates high demands for all the emergency organizations to work together, to carry out their own responsibilities, and achieve the collective goal of limiting the consequences of the attack. Maximizing effectiveness of event management constitutes a defensive counter-terrorism measure-which Perliger and colleagues [2] hold are warranted-instead of focusing only on active offensive methods, as terrorism cannot be entirely prevented.

Active shooter or bombing response scenes present risks of undetonated devices, secondary bombings and shootings against rescue workers [4-6]. Natural or built hazards may also be an issue, e.g., if the attack target is public transportation. This has been the case in some of the more publicized MCAs during the $21^{\text {st }}$ century, like the attacks against the railway sector in Madrid in 2004 (191 fatalities/more than 1500 non-fatally injured people) [7] and on the subway system and a bus in London in 2005 (56 fatalities/775 non-fatally injured people) [8]. Holgersson and Björnstig showed that there was a large increase in non-fatally injured people resulting from the mass-casualty attacks ( $\geq 10$ fatally injured and/or $\geq 100$ non-fatally injured) on public transportation during the years 2000-2009 compared to the previous three decades of the study period. Simultaneously, attacks against terminal buildings, multiple targets, and using complex tactical approaches increased during that decade [1]. This may imply that preparedness among contemporary emergency organizations needs to include the ability to manage large numbers of injured people, possibly at multiple locations, including confined or collapsed spaces, in a hostile and hazardous environment.

Few health care providers have any experience in true mass-casualty incidents with the imbalance between the immediate medical need of a large number of victims and local medical resources [9]. Furthermore, civilian terrorist bombings represent unique challenges to the trauma system, e.g., they often include an urban setting, security and field triage challenges, distinctive injury patterns, and a rapid transfer and distribution of casualties to appropriate hospitals [6]. Victims of terrorist attacks may also present a combination of blast, blunt, penetrating and burn injuries. Blast injuries may be particularly challenging to diagnose and manage, as they may initially may be occult, with no visible signs of injury [10-15]. The setting of modern urban terrorist bombings also means that civilian medical systems are confronted with patients arriving at the hospital alive who would likely have died of their injuries in previous conventional war settings [6]. Moreover, there is a difference in those at risk of injury in a military setting versus those in a civilian setting, where the civilian environment includes children and the elderly [16-19]. Antagonistic acts thus result in injuries that are not commonly encountered in the civilian environment and also augment the challenges of an unintentional mass-casualty incident by adding the factor of a hostile environment which together, demand other approaches by the responders on scene. In-depth studies of previous responses are one way to enable preparation of a more effective emergency response in the immediate aftermath of an attack [9,20].

The aim of the review was to analyze research on challenges for on-scene responses to mass-casualty attacks and suggestions made to counter these challenges, with special attention given to attacks on public transportation and associated terminals. The discussion considers how overarching findings can be used in efforts to increase preparedness.

\section{Methods and Materials}

This integrative literature review set out to generate new knowledge about responses to attacks through review, critique and synthesis of representative literature in an integrated manner [21]. Searches of the databases PubMed and Scopus, as well as references from extracted articles, were conducted in order to limit the risk of systematic errors. Previous studies have indicated that one database search is not enough to find all the studies that have the potential to answer a research question [22]. Searches were conducted in MEDLINE (PubMed) and Scopus in July 2014, and again in May 2015, for articles about on-scene response to terrorist attacks (all published between 1970 and 2015 in the English language). In PubMed, several test searches - with different MeSH-terms, free text words, and filters-were conducted in order to find a balance between a too-narrow and a too-broad search [22]. Components identified as search clusters in order to find articles of interest were: intentionality (weapons, explosions and terrorism), target (transportation), and consequence and management (wounds and injuries, disasters, emergency responders and emergency medical services). All words were used as MeSH-terms except for "terrorism" and "transportation", which were also used as "free text keywords": these terms led to the identification of relevant articles while simply having them as $\mathrm{MeSH}$ terms meant erroneous exclusion of relevant articles. One word from each cluster needed to be present for the article to be found in the search. A similar search was conducted in Scopus thereafter in order to find more articles related to the police and rescue services, complementing the medical perspective more prominent in PubMed. Slightly different keywords and clusters were used as MeSH terms could not be used in Scopus and the aim was to identify more articles regarding the police and rescue service (Table 1). For each title selected, additional titles of interest were also found through the box "related citations in PubMed" or the box "related documents" in Scopus. 
Table 1. Database searches.

\begin{tabular}{|c|c|}
\hline Database & Search strings \\
\hline PubMed & $\begin{array}{l}\text { ((“Explosions"[mesh] OR “Terrorism"[mesh] OR “Terrorism”[All Fields] OR "Weapons”[mesh]) AND ("Transportation”[mesh] OR } \\
\text { "Transportation”[All Fields]) AND (“Disasters"[mesh] OR "Wounds and Injuries"[mesh] OR “Emergency Responders"[mesh] OR } \\
\text { "Emergency Medical Services"[mesh])) AND "English”[Filter] }\end{array}$ \\
\hline Scopus & 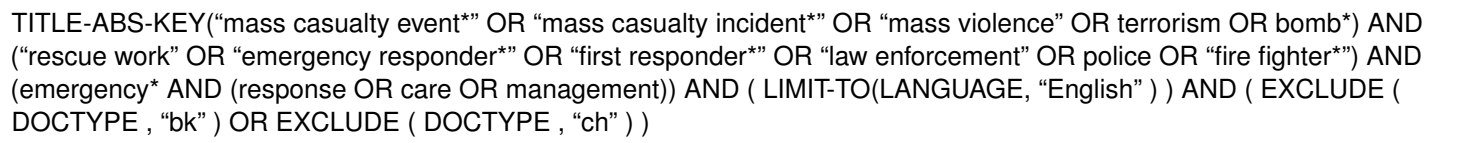 \\
\hline
\end{tabular}

Articles of interest were reviewed in a staged manner: firstly, through readings of their titles; secondly, the chosen abstracts and then the full texts were examined to confirm that they did not meet the exclusion criteria, but met the inclusion criteria:

\section{Inclusion criteria}

(1a) attack(s);

- Specified attack or compounded analysis from several attacks

- Actual attacks/incidents as opposed to simulations or theoretical models

- Irrespective of number of casualties, as long as they were enough to trigger a formal civilian mass-casualty response in the society in which they occurred

AND/OR

(1b) public-transportation-related incident;

- Attacks in connection to public transportation and unintentional incidents with similar injury mechanisms, i.e., explosions and fires

AND

(2) which raised issues of concern for formal on-scene response

- As stated in the MIMMS framework (Hodgetts \& Mackway-Jones 1995; 2004; see below)

\section{Exclusion criteria}

(1) Chemical, biological, radiological, and nuclear (CBRN) attacks

(2) Exposure to "World Trade Center air pollutants"

(3) Long-term psychological and physical sequelae for victims or responders

(4) Management and identification of human remains

(5) Ethical considerations during and after incident management

To determine inclusion or exclusion of articles, relevance to the aim was deemed to weigh more than strict scientific standards and methodology. The reference lists of the selected abstracts were searched for further relevant articles based on titles, and those articles were read in full. Lastly, the final selection of articles was made, further excluding those texts that after scrutiny failed to meet inclusion criteria 2 , i.e. did not contain detailed descriptions of challenges during civilian incident management. This inclusion criteria also meant that reports of incident management without formal prehospital response were excluded, which implies inclusion of articles mainly from OECD countries. The findings are therefore applicable primarily in such contexts.

To assess the scientific quality of each included article, an adapted model of evidence hierarchy was created (including study designs; Figure 1), based on evidence ratings and descriptions of study design from the medical field [22-24]. However, research regarding disasters, crises, or mass-casualty incidents is not limited to health and medical science fields. The subject also presents intrinsic research challenges and is not an area that can be approached through experimental studies such as randomized-controlled trials (RCT). This does not imply that it cannot be the subject of rigorous research, but rather necessitates an adapted evidence hierarchy model that includes the types of studies involved in this multidisciplinary research field. The study design and method by which the research is carried out and presented, constitute integral parts to the assessment of a study's quality. Different study designs are suitable depending on the research question, but certain study designs are generally allotted higher evidence value, illustrated by schematic pyramids of evidence hierarchy where the studies higher up the pyramid are assigned higher evidence value, given that they are properly conducted and described [22,23]. Meta-analyses and RCTs were excluded in the adapted model, as there were no such studies included in the review, while systematic reviews and cross-sectional studies were considered a basis for high-quality evidence. The articles constituting medium evidence-based studies were the "retrospective case series" (a research design normally seen in the medical field), the "comparative case studies" (a research design used within the political science field), and "case studies". Lastly, non-systematic reviews, guidelines, special reports, consensus statements, and perspective articles were considered to have lower evidence value, mainly due to lacking or no presentation of aim, methods or references in these articles. 


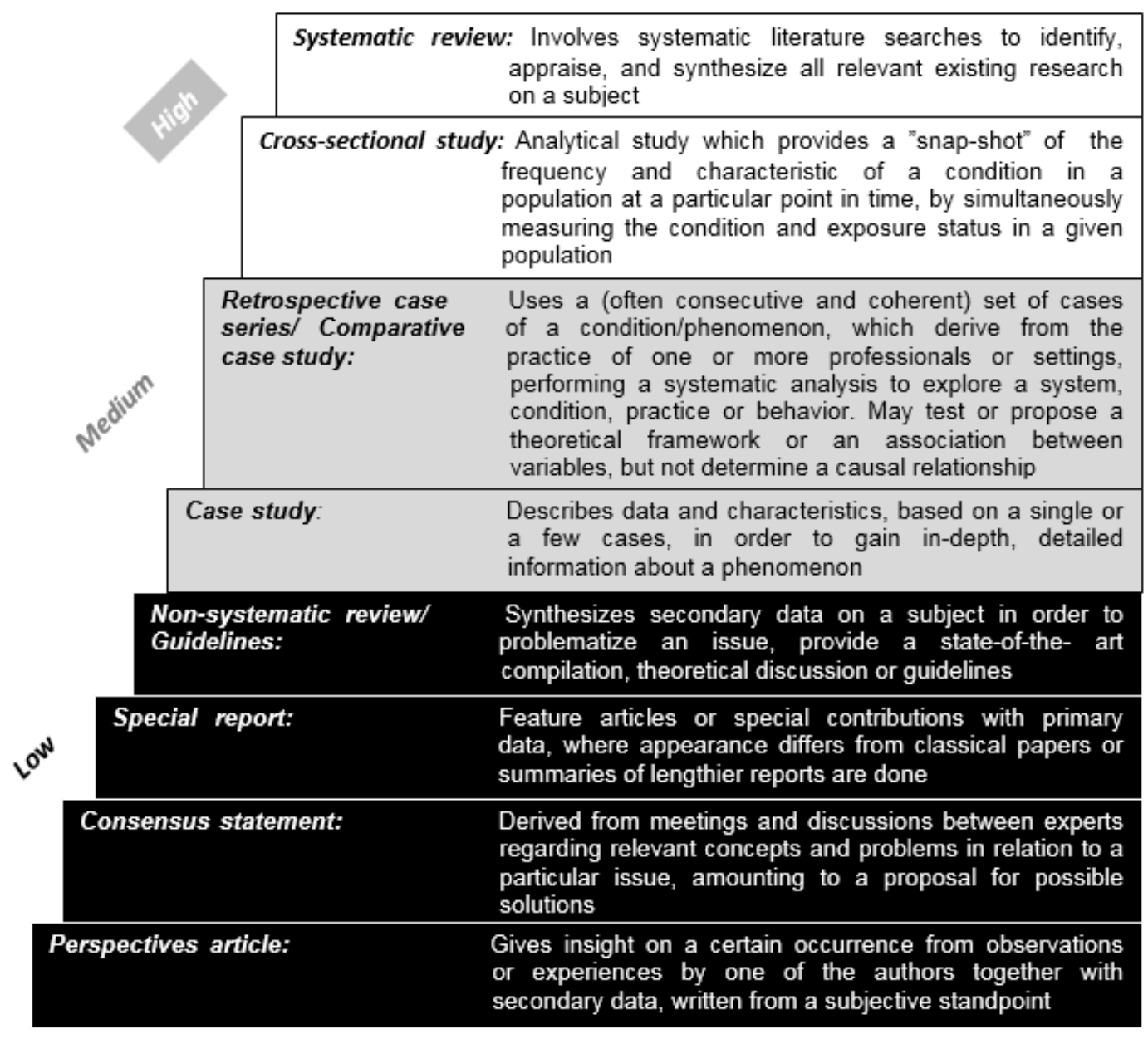

Figure 1. Evidence hierarchy, for scientific quality assessment, including study design description. (E.g. This review would fit with the description of a "systematic review", due to its systematic and appraising nature and the ambition to synthesize existing research on MCA management).

The internationally used Major Incident Medical Management and Support (MIMMS) framework, a systematic, pedagogic model of command and management at the scene of an incident [25,26], constituted the baseline for extraction and sorting the results. This was chosen as it includes details that concern the study's target population of the police, rescue service, and ambulance staff, and it has a medical focus that corresponded well with the findings of the literature search. The defined management priorities Command, Safety, Communication, Assessment, Triage, Treatment, and Transport, used in MIMMS, constituted the basis for extraction of information, word-for-word, from the articles. Command entailed issues concerning vertical and horizontal leadership of the overall rescue effort on scene and re-occurring management challenges. Safety included issues regarding the safety of personnel, the scene, and the survivors, with hazards denoting an unintentional safety risk and threat denoting an intentional one. Communication involved issues with transmission of information within and between personnel in the emergency organizations on scene, and along the chain of command, as well as to supporting organizations and facilities and other persons requiring information. Assessment included issues of interest for the ambulance service in or- der to make estimates of the number of injured, severity of injuries, and needs for extra resources and expertise; in this case involving incident scene overview, the influence of the surrounding public transportation environment on injuries, and the work environment. Triage and Treatment comprised issues regarding the prioritization of injured people for medical care and evacuation; as well as the type of injuries after attacks, level of care, and treatment on scene, and the people who provide care. Transport included issues of accessing, evacuating, and distributing injured people to appropriate medical facilities. After the relevant information was categorized, the information was compounded into its core elements and synthesized in subcategories.

\section{Results}

The primary and related article searches yielded 300 titles of interest out of the 1,638 unique articles found in the database searches, as well as 65 "related article" titles and "reference article" titles. Further review of abstracts found that 116 articles appeared relevant to the study, and 105 articles were included in the review after full-text readings (Figure 2 ). 


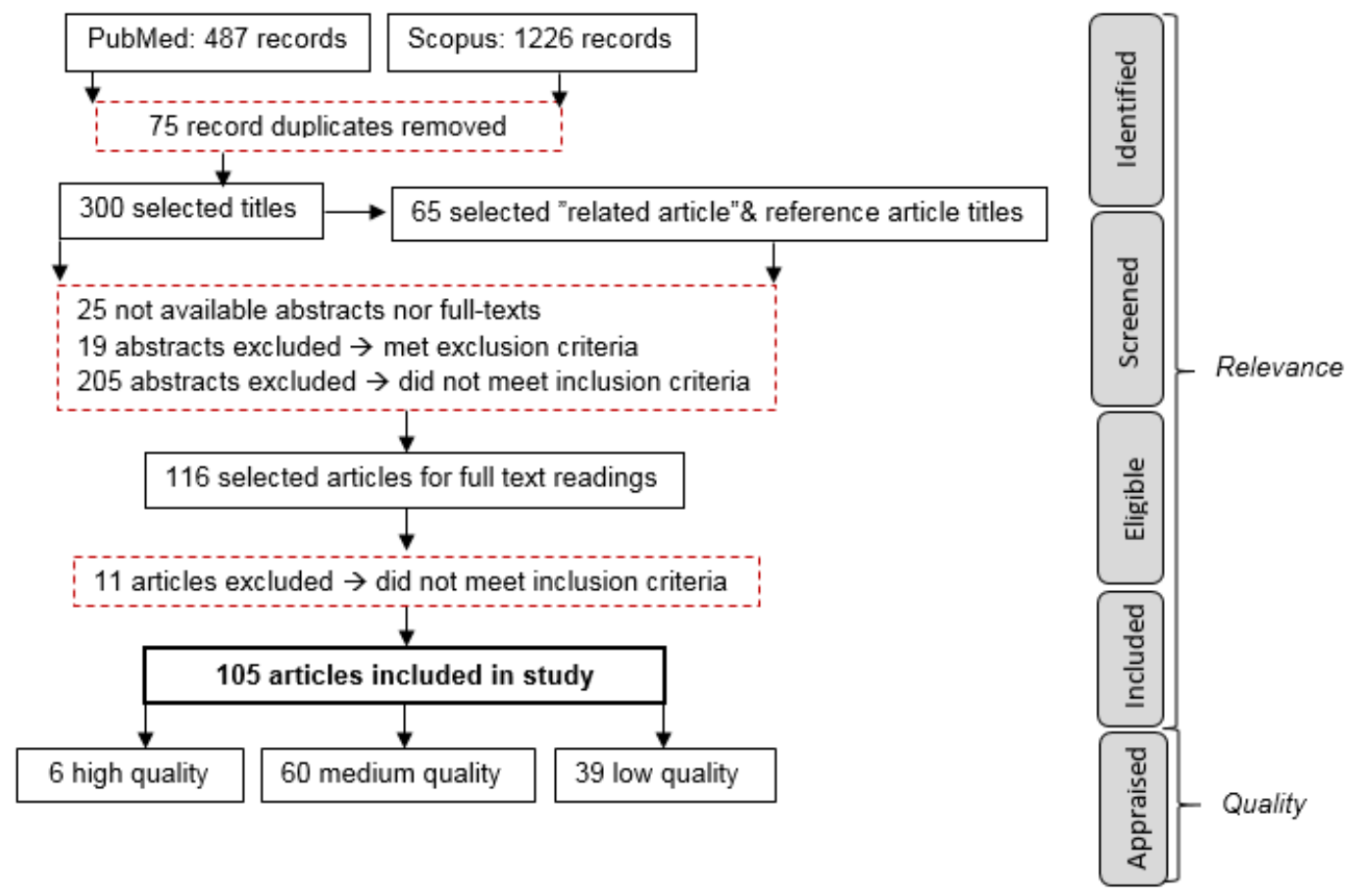

Figure 2. Study flow from identification through screening of relevance and quality.

Of the studies included, three constituted systematic reviews about blast injuries and safety issues, and three articles were cross-sectional studies (i.e., six high-quality studies). Fourteen of the reviewed articles were retrospective case series/comparative case studies and 46 were case studies (i.e., 60 medium-quality studies). Fifteen non-systematic reviews and guidelines, ten special reports, two consensus statements, and 12 perspective articles were identified in the lower part of the evidence hierarchy model (i.e., 39 low-quality studies). Table 2 summarizes the findings of the review regarding the management issues described in the articles, sorted according to MIMMS main management tasks.

\subsection{Command and Coordination}

Traditionally, the first management task is often labeled "command and control", but the articles included in the review clearly portray the essential aspects of coordination, which is why the labeling of this section also reflects this.

\subsubsection{Establishing a Clear, Unified Scene Leadership}

Lack of command, coordination, and integration between the emergency organizations have been commonly reported problems during responses to MCAs [2,27-30]. The presence of several representatives of similar emergency organizations and several responders in a leadership position have also amounted to confusion, contradictory orders, and complications for scene management [30,31]. Early establishment of a common operating picture with all involved agencies gathered in a multidisciplinary, unified command at an Incident Command Post (ICP), has been critical for the synchronization and effectiveness of rescue operations $[4,5,14,32,33]$.
According to Perliger et al. [2], a clear picture of the situation and proper coordination during the first minutes after an attack had a greater effect on the duration of the on-scene management process than the number of medical staff or the number of wounded people. Increased standardization of the command structures, language to manage events, and clear jurisdictions and distribution of duties between the involved emergency organizations, could increase survival $[29,30,34]$.

\subsubsection{Collaborating across Responder Professions in Planning \& Practice}

Inter-agency planning and coordination is regarded as imperative between police, rescue service, emergency medical services, and mental health professionals $[2,5,20,29,35,36]$. Pre-event collaboration plans may also need to include policies for cross-border medical responses [37] and use of military units [37] or specific sea rescue organizations [35]. Priorities on the incident site should not be viewed as sequential. Instead, several actions need to occur simultaneously, carried out by different rescue organizations $[5,29,34]$. This necessitates functional inter-agency collaboration with clearly predetermined, common principles for incident management and defined tasks and responsibilities of each organization, which in turn need to be drilled $[2,5,34,38]$. If responders are not aware of the others' identities, roles, or tasks, problems in the inter-agency cooperation will likely arise [38]. Intra- and inter-agency cooperation and coordination is required for efficient management, but such cooperation is complicated as a large number of teams assemble, each with its own goals, its own organizational terminology, and its own supervision $[2,7,39,40]$. 
Table 2. Summary of defined challenges and corresponding scientific quality of articles.

\begin{tabular}{|c|c|c|c|c|}
\hline \multirow[t]{2}{*}{ Prioritized task } & \multirow[t]{2}{*}{ Management challenges } & \multicolumn{3}{|c|}{ Quality appraisal of articles referenced } \\
\hline & & Low & Medium & High \\
\hline \multirow[t]{4}{*}{ Command \& Coordination } & - Establishing a clear, unified scene leadership & 7 & 5 & \\
\hline & - Collaborating across responder professions in planning \& practice & 6 & 7 & \\
\hline & - Coordinating multi-site incidents \& multi-exit scenes & 2 & 5 & \\
\hline & - Balancing needs for staff \& resources & 2 & 5 & \\
\hline \multirow[t]{5}{*}{ Safety } & - Knowing of \& using personal protective equipment & 6 & 3 & \\
\hline & - Being aware of risks \& having realistic expectations of safety & 7 & 4 & 1 \\
\hline & - Conducting dynamic risk assessments \& cordoning off the scene & 7 & 7 & \\
\hline & - Approaching safety defensively or offensively & 5 & 1 & \\
\hline & • Joining forces & 3 & & \\
\hline \multirow[t]{3}{*}{ Communication } & - Functioning equipment - overload, destruction, \& incompatibility & 10 & 12 & \\
\hline & - Dialoguing - content, language \& relay & 5 & 10 & \\
\hline & - Informing - survivors, relatives \& the public & 4 & 8 & \\
\hline \multirow[t]{2}{*}{ Assessment } & - Viewing scene layout \&interpreting environmental indicators & 9 & 11 & 2 \\
\hline & - Understanding setting-driven needs for specialist skills \& resources & 9 & 8 & \\
\hline \multirow[t]{7}{*}{ Triage \& Treatment } & - Differing triage systems \& labelling & 3 & 12 & \\
\hline & - Directing \& gathering casualties & 6 & 7 & \\
\hline & - Encountering uncommon injuries & 15 & 26 & 5 \\
\hline & - Setting up field hospitals \& personnel matters & 17 & 14 & \\
\hline & - Determining ambition for level of care \& treatment & 10 & 6 & 1 \\
\hline & - Providing psychological support & 7 & 3 & \\
\hline & - Caring for the pediatric casualty & 1 & 2 & \\
\hline \multirow[t]{3}{*}{ Transport } & - Accessing \& leaving the scene & 8 & 10 & \\
\hline & - Evacuating from urban or rural scenes & 5 & 11 & \\
\hline & - Distributing patients & 14 & 18 & \\
\hline
\end{tabular}

\subsubsection{Coordinating Multi-Site Incidents \& Multi-Exit Scenes}

Challenges with coordination have been most commonly seen at events where there has been several incident sites or more than one evacuation point $[2,41]$. When several attacks have occurred simultaneously and in geographically proximal areas, there has been confusion regarding the number of incidents $[20,30]$. This confusion leads to misunderstandings at EMS dispatch about the location of the scenes, resulting in severe maldistribution of medical assets and personnel, and greatly varying levels of treatment [30]. In order to avoid such issues, a functional central command level is essential, as multiple incidents often aggravate communication and coordination problems [20]. Multi-site incidents may also increase coordination demands due to occurrence within a catchment area of several EMS systems or jurisdiction of several involved agencies $[41,42]$. Another problem for incident command may occur if there are multiple exits available from the site, e.g. incidents in tunnels, on ferries or islands, as casualties can escape in several directions. This can result in dispersal of responders and can complicate organization of clearing stations and evacuation, but management may be alleviated by setting up several command posts $[41,43,44]$.

\subsubsection{Balancing Needs for Staff \& Resources}

A study by Juffermans and Bierens [38] indicated that logistics was an issue at all five incident sites researched, often connected to communication deficiencies. Timely and adequate supply of clothing, tools, and equipment is important, e.g., for identification, safety, debris removal, and void searches $[14,45]$. While the definition of mass-casualty incident commonly implies dealing with resource shortage supplying an excess of resources and personnel may lead to difficulties in tracking and locating supplies, problems with coordinating the rescue effort and may delay casualty evacuation $[2,33,39,46]$.

\subsection{Safety}

The principle priority at the scene of an attack is safety of self, scene and survivors $[6,14,25,47]$. Rescue personnel have to face a reality where there is a need to worry about their own and the victims' safety, as well as demands to manage life-threatening injuries [6]. According to Kashuk et al. [6], balancing such safety concerns with expeditious casualty care requires training, in addition to a well-developed work ethics base and, optimally, actual experience. 


\subsubsection{Knowing of \& Using Personal Protective Equipment}

To be able to work on site, all rescue personnel need to be familiar with personal protective equipment (PPE; e.g., helmet and respiratory protection), and the equipment needs to be immediately available in the response vehicles $[43,45]$. Respiratory protection, for example, is not just applicable to minimize inhalation of intentional chemical or biological agents, but also airborne particles present after bombings or after a building collapse [43]. Lack of PPE use by responders has been seen during previous responses, with several accounts of on- and off-duty staff working on scenes wearing scrubs, surgical masks, and clogs [28,44,48-50]. Responders from involved emergency organizations may not be equally aware of the risks to themselves during shooting incidents or of the limitations of their protective gear. Military rounds, e.g., those used in high-velocity weapons, can easily penetrate the sides of a vehicle as well as some bullet-resistant vests [4]. Thus, while they may stop bullets from some guns, it is important not to assume that "bullet-resistant vests" are "bulletproof vests" [4,51].

\subsubsection{Being Aware of Risks \& Having Realistic Expectations of Safety}

Caution is warranted during scene approach, as initial reports may have given the wrong location, and thus rescue personnel may place themselves and their vehicles at risk of unintentional hazard or an intentional threat [4,52]. Following an attack, responders need to consider the risk of secondary explosions or coordinated attacks [20], as attacks are sometimes arranged to create a need for a rescue effort through an action, to then target rescue personnel on arrival $[4,7,9,33]$. Several case studies however, tell of lapses in determining presence or absence of secondary explosives [30,44], and undetonated devices have been present at several attack sites $[30,44]$, implying that personnel have provided treatment and placed casualty tents within the risk zone of undetonated devices $[7,30]$. In one case, the police collecting belongings unknowingly brought an undetonated device to the police station [7,30]. As opposed to responses revealing a lack of risk awareness, exercises have also revealed unrealistic expectations of safety at hostile event scenes by EMS and fire services. The difficult and time-consuming practice of waiting for a full risk assessment could delay provision of life-saving care [53]. Thus, it is not always possible to secure the entire site quickly enough to refrain from continuing the rescue effort. Responses to MCAs may require a transition into thinking of "relative safety" and "plus one" threat (e.g., looking for secondary devices or a perpetrator among the victims)-a frame of thought implying wariness of safety threats without expecting the entire scene to be secured before acting [5]. In a systematic review, Thompson et al. further showed that while the scene of a terrorist attack includes direct threats, the published literature suggests that dominant causes of mortality and morbidity in responders after such incidents have been due to indirect environmental hazards [54].

\subsubsection{Conducting Dynamic Risk Assessments \& Cordoning off the Scene}

Scene safety includes assessing and ensuring the immediate safety of the incident scene from both present threats and potential hazards, which need to be continuously reevaluated by way of a dynamic risk assessment as the rescue and tactical situation may change $[40,43,48]$. If there are no set policy decisions regarding whether to go in or wait, i.e. "rules of engagement", the decision ought to be made by someone with management responsibility and not left to individual responders [43,53]. During MCA responses, there is a need to move people away from the scene $[8,20]$, i.e., evacuate casualties, distance civilians, perform crowd control [34], and control access by checking personnel identification [9]. A suitable division of a scene may be one with three cordons, similar to those used in the UK [20]. In a schematic representation (Figure 3), the "middle cordon" could be an established safe area, functioning as a buffer area, allowing for triage and life-saving treatment of casualties outside of the immediate danger area found in the "inner circle". The "outer circle" would then contain the designated evacuation roads, identification control, and searched buildings. The police's ability to create and regulate the cordons is an essential task for alleviating management and provision of important medical procedures and hindering follow-up attacks $[20,33,46]$. Cordons also constitute an important measure to protect forensic evidence and control the flow of personnel and traffic [14], but they need to operate while minimizing barriers for essential equipment, staff, and patients [2,42,55], through pre-determined plans and functional inter-agency cooperation [2].

\subsubsection{Approaching Safety Defensively or Offensively}

Approaches to scene safety and management on scene differ throughout the world, depending on the local context, governance, and experiences of attacks. Based on conflict experiences in Colombia, responders do not enter a scene without governmental provision of troops in order to assure security [20]. Experience with follow-up attacks in Israel has led to the enactment of different regulations at different times [32,33]. At one point, regulations forbade medical forces from entering the scene until the police had given the all-clear, but these were not strictly adhered to, and opposite policies have also been described where EMS do not wait for security clearance [33]. Instead, wearing their mandatory protective gear, they attempt to remove casualties from the immediate vicinity of the initial event, only providing external hemorrhage control before doing so [32]. The first example describes a more defensive approach to safety while the latter tells of a more offensive approach. The offensive approach implies an aggressive entry into an unsecured scene containing casu- 
alties, followed by rapidly addressing correctable trauma and promptly evacuating victims in a joint entry involving police and medical personnel [5]. The 1999 Columbine school shooting constituted a watershed incident in the development of the more offensive approach, leading the police to adopt an "active shooter" tactic. During similar incidents, the tactic implies that police rush into the building and attempt to end the threat instead of awaiting the Special Weapons and Tactical (SWAT) team. At the time of the Columbine shooting, the previous tactic led to some of the fatalities and morbidity among casualties due to unchecked hemorrhage and chock, as a result of delay in threat neutralization and care. Use of the changed tactic has allowed tactical medics to provide care before entire scene safety clearance $[29,58]$. The change in tactics have also resulted from experiences of combat trauma, which can amount to similar injury patterns as those in active shooter incidents and terrorist attacks. Thus, the prehospital guidelines of Tactical Combat Casualty Care (TCCC), customized for use on the battlefield to avoid common causes of preventable death in combat, have increasingly gained acceptance in the civilian trauma care system and the principles have been adapted into different training programs for care during civilian tactical situations [29].

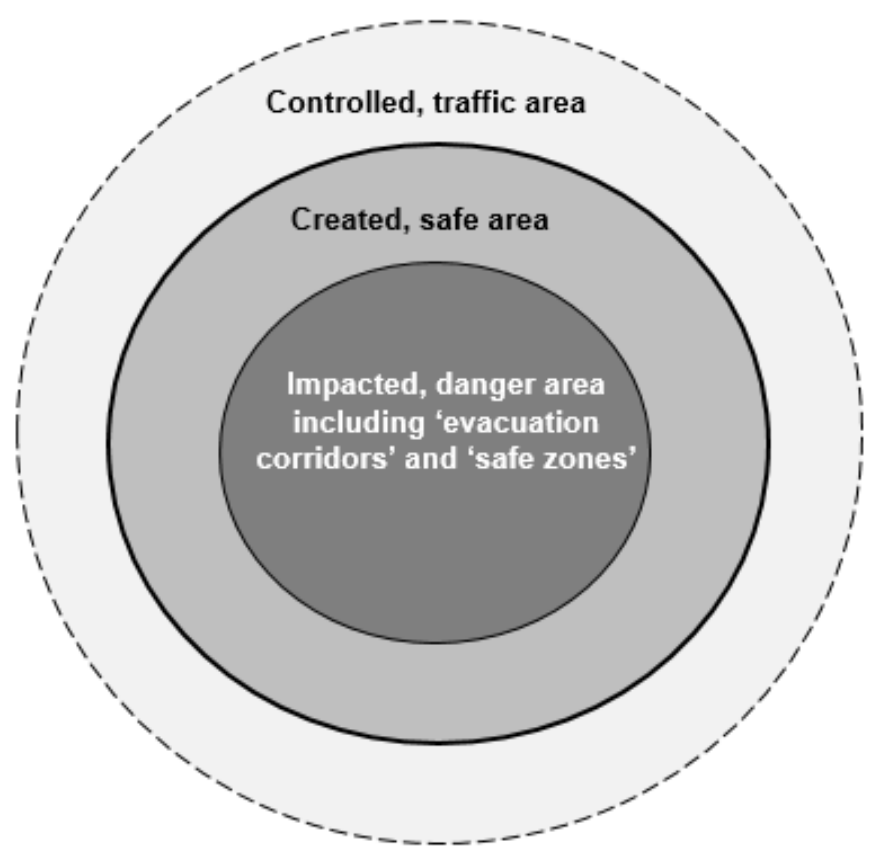

\begin{tabular}{|c|c|c|}
\hline Zones within & Force & Task \\
\hline \multirow{5}{*}{ Danger area } & Police & $\begin{array}{l}\text { Neutralize/estimate threat, Identify casualties, } \\
\text { Create safe corridors }\end{array}$ \\
\hline & EMS & $\begin{array}{l}\text { "Rapid security check", Evaluate, Apply tourniquet } \\
\text { as needed, Evacuate to safe zone }\end{array}$ \\
\hline & Rescue services & $\begin{array}{l}\text { Assist extrication of trapped casualties, Clear } \\
\text { wreckage. Assess environmental hazards }\end{array}$ \\
\hline & Bomb squad (if available) & Search of additional devices \\
\hline & Forensic team (if available) & Gather preliminary evidence \\
\hline \multirow{4}{*}{ Safe area } & Police & $\begin{array}{l}\text { Search the premises, Create cover, Control } \\
\text { access }\end{array}$ \\
\hline & EMS & Triage and treat casualties \\
\hline & Rescue services & $\begin{array}{l}\text { Create cover, Provide equipment and support to } \\
\text { EMS }\end{array}$ \\
\hline & Mental health professionals & Assist police investigation, Aid minor injured \\
\hline \multirow[t]{2}{*}{ Traffic area } & Police & $\begin{array}{l}\text { Cordon off, Control access, Distance civilians, } \\
\text { Establish evacuation route, Search buildings close } \\
\text { to and with clear line of sight to scene and } \\
\text { evacuation routes }\end{array}$ \\
\hline & EMS & Evacuate \\
\hline
\end{tabular}

Figure 3. Schematic summary figure of response on the scene of antagonistic attacks, depicting zones of action and essential tasks by personnel of the responder forces (adapted from Almogy \& Rivkind 2007 [34], Jacobs et al. 2014 [29]; Autrey et al. 2014 [5]). 


\subsubsection{Joining Forces}

Traditionally, the responsibilities and responses of the emergency organizations to MCAs have been viewed as separate actions conducted sequentially. However, death due to exsanguination from a proximal extremity vascular disruption can occur in as little as 4-5 minutes, implying that the typical sequential response of law enforcement followed by EMS and rescue services cannot happen fast enough to avoid preventable death $[29,56]$. The resultant need for an integrated response of the emergency organizations increases inter-agency dependence and requires joint training as well as raised awareness in risk assessment. This is to enable an adaptable response to the situation in terms of safety risks and the need to provide care [5]. Autrey et al. [5] described an approach that guides the initial 30 minutes of a response to a blast or active shooter event, which can be remembered through the mnemonic "3 Echo", representing "Enter", "Evaluate", and "Evacuate". In an effort to deal with the dilemma of responder safety (entering a scene too early) versus delayed care to victims (entering a scene too late), the approach presents the use of "evacuation corridors" to gain access to victims by initially securing functional areas instead of the entire site [5]. In accordance with the 3 Echo principles, during a mass-shooting police immediately entered the building to contain and neutralize the threat. Simultaneously, locations of casualties were identified and communicated to incident command. Additional arriving support began to create cover, establish cordons, create command, staging areas, and coordinate medical asset deployment. Next, a secondary group of police officers gained access to identified casualties and secured the immediate area where they were located, rapidly identified viable victims, developed an evacuation corridor from a safe point of entry, and called in EMS from the staging area. EMS personnel then entered the secured corridor under police escort, and injured casualties were rapidly body swept for weapons and immediately treated with tourniquets if needed. Then, they were evacuated along the corridor to safe staging before being rapidly transported to a suitable health care facility. Police security screened the walking wounded as they were guided out of the hazard area to assembly areas for treatment on scene or medical transportation [5].

\subsection{Communication}

The key to a successful response is effective communication [57], but communication problems have been reported as one of the most common, and most serious, challenges in MCAs $[2,9,20,31,35,38,39,44,46,58-60]$.

\subsubsection{Functioning Equipment-Overload, Destruction, \& Incompatibility}

One of the most frequent problems with communication is technical inadequacy, shown by overload of landline tele- phones, mobile networks, and radio-channels on walkietalkies [7,20,28,30,31,39,42,44,46,53,61-65]. Equipment failure has also been caused by actual physical damage to the communication infrastructure $[40,64,68]$. Incompatible equipment and separate coordination centers between involved emergency organizations and between civilian and military actors have likewise caused communication and cooperation problems $[30,65]$. Consequences of equipment breakdown include inability to call in more staff or resources, failure to keep track of units on scene or inform them of safety issues, or prompting staff to drive to the scenes without knowing where to respond and stage $[39,42,62,66]$. To overcome communication shortfalls on scene, hand-held megaphones, runners, and hand signals can be used, but hand signals would require clear visibility and prior training $[20,32,35,42]$. Two-way radios with dedicated channels have often provided a good communication alternative, but it can be impeded in some locations, such as the subway, near crash sites, and in buildings [6,44,67]. Other communication solutions seen have been cellphone providers donating phones and activating reserve system capacity [46] or an alternative system for emergency communication only [62]. For maximum effectiveness, schemes of access overload control need to be pre-arranged [57]. The procedure could also permit the police to block cell phone frequencies in certain areas to prevent potential activation of secondary devices, without leaving units on scene deprived of means of communication [30].

\subsubsection{Dialoguing-Content, Language, \& Relay}

While functional equipment is a prerequisite for functional communication, communication breakdown might still occur due to failure in the process of exchange of information, e.g. due to absence of training, poor compliance with basic principles for communication or lack of routine procedures for relaying information $[2,33,38]$. Functional communication between and within organizations is important [2] and may be eased through use of a common lexicon to avoid different interpretations of terms used [20]. Language barriers between the responders and casualties as well as temporary deafness of bombing victims have constituted other communication difficulties $[20,35,68,69]$. Problems with relaying information between responder units have coincided with large incident scenes and units divided into sub-zones [70]. Information relay has also been problematic due to noise levels, e.g. by helicopters with rotors [35] and heavy machinery [48]. Information relay between the incident site, EMS, and the emergency department (ED) have been lacking repeatedly, e.g. regarding the size and complexity of the incident $[8,20,28,30,53,71]$. Transmitting and documenting detailed information about the patients constitutes another challenge during MCAs as initial triage, treatment, and transfer is often conducted by different responders, with little or no contact among them. This means essential patient data and valuable time is lost repeatedly throughout the caregiving process [30]. Several researchers therefore 
stress the need for documentation and information transfer, e.g., through easy-to-read triage tags $[30,66]$.

\subsubsection{Informing-Survivors, Relatives \& the Public}

Communication does not only need to function between people involved in the rescue effort, information also needs to reach survivors, relatives, and the general public. Keeping relatives and victims informed may prevent problems post-trauma [62]. Moreover, clear communication with the public, providing simple information, directions, and advice regarding what has happened and what to do, may calm fears, discourage people from assembling at hospitals and incident scenes, and lessen calls to emergency dispatch $[20,28,39]$. Setting up a transfer procedure or hotline for "incident-related calls" may alleviate pressure from the dispatch center [20,63]. Arranging a temporary Crisis Information Center or Family Assistance Center, staffed by psychologists, nurses, and social workers, have been other examples of aids to help identify and locate victims and retrieve information regarding their condition or liaise between other supportive services $[67,72,73]$. A method for dealing with the media ought to be included in emergency plans [46]; previous incidents have shown that if information and clear directions are not given, there may be dissemination of misinformation, hospital referral numbers, or unauthorized calls for volunteers $[48,61,65]$. While the media have been known to contribute to collapses in communication, there have also been examples where television and radio channels have worked as a means of mobilizing staff [62].

\subsection{Assessment}

All involved organizations make their own assessments of the scene reflecting their responsibilities and expertise, but this section focuses on the EMS organization in accordance with the reviewed articles. In order to enable an organized response, one person on the first medical team on scene is appointed "medic in charge" or "medical incident commander" (MIC). The role implies focus on facilitating the EMS chain of command by being the eyes and ears "on the ground" and transferring this information to EMS central command. This assessment process is started by refraining from rendering medical help, concentrating instead on a rapid scene assessment and communicating to EMS central command: (1) the Exact location of the scene; (2) Type of event; (3) present and potential Hazards; (4) Access via primary routes for approach and evacuation, and the location of the Incident Command Point; (5) the estimated Number (few, tens, hundreds) and severity of casualties; and (6) Extra resources needed $[6,25,32,34]$. These crucial pieces of information may be recalled by the mnemonic "ETHANE". "METHANE" may also be used, where the "M" denotes declaring a "Major incident", but doing so and activating disaster plans is not always an authority given to prehospital personnel [26].

\subsubsection{Overviewing Scene Layout \& Interpreting Environmental Indicators}

Layout of the scene has been an observed complicating factor lengthening the time between the emergency call to completion of the evacuation [2,23]. Making a first assessment and establishing control is more difficult if the scene is divided into natural sections that are difficult to overview, such as a railway platform [30] or involving large structures like buses or trains [2]. Such situations have been managed by adding to the chain of command, where arriving units are assigned geographic zones and may report to a specific commander for the area or directly to the medic in change [32,34,70].

In Israel, the number of "lying wounded" is used as a surrogate for seriously injured casualties [34], but several environmental indicators may be used to estimate the number of casualties at the scene of a bombing. Simply identifying the place and size of the affected area together with the time of day or week, one may be able to estimate the demographics and numbers of casualties expected [15]. With regard to attacks targeting buses and trains, in terms of estimating number of casualties, it is important to consider the risk of ejection from the vehicle and entrapment under it [74] as there have been examples of such bombings causing some of the passengers to be ejected up to 100 meters [37].

Frykberg defined several prognostic factors affecting casualty outcome of bombings, which can be observed or estimated during the initial assessment of the scene: magnitude of explosion, urban versus isolated setting, closed space versus open-air setting of bombing, and building collapse [9]. The type of bomb has different repercussions in terms of scale of destruction and likelihood of producing mass casualties. The size of the zone at risk is dependent on the type and amount of explosives, the environment, and the size of debris. Explosives hidden in a backpack are capable of producing mass casualties and causing building collapse, despite being limited in size. A car bomb, again depending on explosive type and quantity, is capable of causing destruction over a $500 \mathrm{~m}$ radius and may be detonated remotely or driven close to a target [75]. If the explosives are carried on their person, the destructive force of a suicide bomber also limits the amount of explosives that can be used [20], but the destructive force is often amplified by the use of high-grade explosives, a load of heavy shrapnel, and the additional ability of the attackers to detonate the explosive device in proximity to victims [73].

Many of the reviewed articles involve the effect of the setting on mortality and injuries of casualties in an indoor versus an open-air setting. There is some debate about what to call these settings, but the bottom line is that the more confined the space, the higher the rates of mortality [6]. Open-air (OA) bombings, e.g. in outdoor cafés or bus stops, result in fewer casualties than those detonating in a confined-space (CS) setting, in addition to having lower immediate, and late, mortality rates [16,76,77]. Casualties of OA bombings, however, show higher rates of penetrating 
soft tissue injury due to shrapnel, which are mostly minor and can often be treated and released [78]. While Leibovici et al. [79] classified bus bombings as confined-space bombings, Kosashvili et al. [16] stated that bus bombings should be further distinguished from other CS settings, such as restaurants and nightclubs. Instead, buses ought to be considered an ultra-confined space (UCS), because buses constitute a smaller confined space, leading more people to be closer to the explosion center. Furthermore, the people in the immediate vicinity of the explosion are not the only ones in danger: the more distant passengers will also be at risk of injury due to rebound amplification of the blast wave as it is reflected [16,80]. In Kosashvili et al.'s study of 12 consecutive suicide bombings, the bus settings led to higher rates of overall mortality compared to CS bombings in buildings and OA bombings, but smaller rates of moderate and severe injuries as more individuals were exposed to lethal pressure from the blast wave. Meanwhile, lower immediate mortality rates (16.9\%) were seen in CS bombings, compared to buses $(21.2 \%)$, but higher rates of moderate and severe injuries, often involving multiple systems and requiring urgent surgical treatment. Almogy et al. [73] also found a difference in severity of injury between the three settings; a median number of 11,8 , and 5 casualties were in need of hospital admittance after bus, CS, and OA bombings, respectively. One may extrapolate that vehicles, such as trains and airplanes on the ground, will be similar to a bus setting, while subway trains in tunnels constitute an even more extreme setting, as they are doubly contained. In a comparison of the four scenes of the London bombings in 2005, mortality was highest and amputations were most numerous at the scene where the explosion took place in a carriage in a single tunnel [80]. The highest immediate mortality rates from bombing settings have been seen in bombings that resulted in structural collapse, and people located in a collapsed region of buildings have been significantly more likely to die or require hospitalization [73,81]. In the 1995 Oklahoma City bombing, $45 \%$ of those who perished were in the building that collapsed [61].

\subsubsection{Understanding Setting Driven Needs for Specialist Skills \& Resources}

The scene of an attack often entails difficult working conditions, sometimes compounded by a public transportation target that adds hazards and challenges on scene, necessitating specialist training, extrication skills, and equipment for an efficient rescue $[43,44,52,60]$. Otherwise, surrounding hazards can delay both EMS access to victims and evacuation, in turn affecting mortality since the probability of saving critically injured victims greatly decreases with time $[5,46,74]$. In connection to public transportation, hazards are fuel ignition, electrical current, and surrounding traffic; issues which need to be dealt with before rescue is started $[30,39,52]$. Incidents in underground locations often entail difficult working conditions; for example, poor ventilation means airborne dust, smoke and high temper- atures, lack of lighting means working by flashlight, and access to debris-filled carriages requires use of ladders $[44,60,69]$. Vehicle stabilization may be required before work in train carriages or buses is initiated [52], and the dynamic risk assessment needs to include re-evaluation of stability and other safety issues as responders, casualties, and equipment move around the vehicle during extrication procedures $[43,52]$. Noise caused by a large number of rescue workers can also reduce possibilities of hearing buried victims in incidents which have amounted to building collapse. Quickly cordoning off such sites and limiting personnel could thus increase likelihood of finding victims in the debris [82]. Attacks occurring at sea present special prehospital challenges when rescue is additionally complicated by the vessel structure, number of passengers, isolation, distance, and limited evacuation means [35]. Such incidents may also entail environmental hazards during rescue, e.g. water current, underwater obstacles, and rapid temperature loss, so personnel entering the water ought to be trained and equipped [52]. Other hazards during scene management have included hot ground temperatures, high debris piles and falling debris, smoke, dust, stored gases, liquids, and ammunition [39,45,47,48,71,83]. Geographic information systems (GIS) have proved essential to managing hazards by illustrating security and safety zones, building damage, and disposition of relief assets, presenting possibilities for the future where GIS professionals may serve as "information first responders" [48].

\subsection{Triage and Treatment}

While "triage" and "treatment" are divided in MIMMS, here they are presented together as the issues are closely interrelated in the management of injuries on scene.

\subsubsection{Differing Triage Systems \& Labeling}

The goal of field triage is to identify that minority of critically injured (salvageable) casualties who need immediate care, provide them with lifesaving procedures, and assign the casualty priority for further treatment $[18,32,50,84]$ and transport, accounting for the casualties' need for treatment at a hospital as well as considering hospital capability and capacity $[18,32,84]$. In order to denote the different triage categories, numbers, colors, or symbols may be used [18] on tags [50] or tape [16] attached to the casualty. They could also be directly drawn on with permanent marker [85]. There are several different triage systems used, with two to five categories [20] utilized to mark the condition of the casualty and/or priority for medical evacuation. For large-scale responses, which may require action by several EMS organizations, standardization of triage systems is important. It is not only considering choice of triage system that is important but also addressing what should be the foundation and indicator for the labeling to avoid being left up to the interpretation of each responder $[30,35]$. Many previous incidents have shown the use of a planned or improvised, simplified, 
two-category triage, dividing casualties into an "urgent" or "non-urgent" group $[8,35,46,70,72,86,87]$. While triage into more categories is likely suitable at the ED, there may be a reason to evaluate whether a wider use of a simplified triage for MCAs is appropriate in the prehospital setting [8].

\subsubsection{Directing \& Gathering Casualties}

The assigned triage categories are divided into triage sites established in searched, cleared, and secured areas away from the scene, where surviving casualties and medical personnel are protected from further hostilities [9,14,34]. The great majority of injuries suffered by immediate survivors of bombings are mostly non-life-threatening, resulting in "walking wounded" people who can be temporarily gathered, observed, and treated in a designated area together with other non-urgent casualties, while being given and supplying information $[32,34,88]$. While the duration of a suitable observation period may be under question with regard to bombings, one study showed that all cases of pulmonary primary blast injury developed within 1 hour [15]. A high incidence of anxiety and other-stress related phenomena often follow bombing incidents, which implies that many mildly injured patients will require psychiatric evaluation. As an emotionally traumatized person may require both medical and psychosocial support for years, substantial treatment of non-urgent casualties also constitutes a part of a good initial response [89]. Achieving early site control and informing walking-wounded individuals where to go for assistance constitutes an important measure for their safety and keeps them from independently deciding where to go, resorting to "self-evacuation" [15,20,47]. As complete use of EMS for evacuation has been rare [42,47,90], pre-event plans should consider self-evacuation inevitable and have procedures to manage it, e.g., by preparing a separated area of treatment of mildly injured people close to the ED at the nearest hospital or by treating and releasing casualties with minor injuries gathered at the scene, or sending them to more distant hospitals, to avoid overwhelming proximal facilities [32,86,89,91]. Directing non-urgent casualties to a separate triage area allows most of the EMS work on scene to focus on those with more urgent injuries [20,34].

\subsubsection{Encountering Uncommon Injuries}

Different types of attacks obviously result in very diverse patterns of injury and medical needs, but the focus of this study has mainly examined research related to bombings. Previous armed assaults however, have shown that gunshot victims have a higher propensity for moderate injuries compared to blast victims, as well as slightly higher inpatient mortality, which creates critical need for immediate resuscitation [92]. Shootings therefore create great demands on prehospital care and rapid evacuation in order to decrease mortality of the critically injured $[29,56]$. While identification of gunshot injuries can be more straightforward [87], detonation injuries may be problematic to diagnose and treat, and are uncommon in most civilian settings $[6,10,11,15]$. Bombings, however, constitute the most common way to perpetrate terrorist attacks [75], which is why some aspects relevant for triage and treatment of blast injuries in the prehospital stage will be presented more in depth.

A characteristic injury pattern of bomb explosions is one of a complex but often non-lethal nature, where most casualties do not require hospitalization as only a small number have severe injuries $[9,32,39,55,62,75,82,90,93-96]$. The vast majority of deaths from bombings usually take place at the scene or en route to the hospital, followed by few early and occasional late deaths $[17,58,62,97]$. In a study of 33 MCAs, Einav and colleagues [96] found that roughly a fifth ( $n=236 ; 20.4 \%$ ) of the injured were considered urgent casualties. Consequently, a large majority of surviving victims can likely be triaged and treated on an outpatient basis $[17,97]$. Medical preparedness should anticipate most injuries from bombings to be nonfatal secondary and tertiary blast injuries $[9,10,44,81,97]$. Personnel responding to the scene of a high-explosive detonation will be confronted mostly with injuries comprising conventional blunt, penetrating, and thermal trauma, but they need to be wary of the less common, potentially life-threatening primary blast injuries, which may present subtly or delayed [15]. Even with no detectable external trauma, there is a risk of primary blast injuries, e.g. to the lungs or bowels. This needs to be considered, especially in casualties categorized as non-urgent $[12,34,79,82,97,98]$.

Trauma after explosions is often divided into primary, secondary, tertiary, and quaternary injuries [9,15,84]. Primary blast injury (PBI) occurs as a direct effect of changes in atmospheric pressure caused by a blast wave, mainly injuring gas-containing organ systems, notably the middle ear, the lungs, and the bowel [15]. Blast lung injury (BLI) is not the most common injury, but it causes the greatest morbidity and late mortality from blast effect and may be complicated by pneumothoraces or hemothoraces [47,99]. Early recognition of BLI may improve outcome by directing patients to an appropriate level of care and initiating early treatment [77]. Clinical signs and symptoms of BLI include dyspnea, chest pain, hemoptysis, hypoxia, and/or wheezing [47]. Abdominal blast injuries are rare, but if the casualty displays clinical signs such as nausea, vomiting, or abdominal pain, they need to be aggressively treated, with serial abdominal examinations and nothing given by mouth $[9,47]$.

A long-cherished belief among rescuers has been the examination of the tympanic membrane to quickly triage victims for other primary blast injuries [100], but several studies $[13,76,101]$ have shown that tympanic membrane rupture (TMR) is neither a reliable predictor of other PBI, nor a reliable method of diagnosis. Presence of a perforated eardrum may indicate exposure to significant overpressure, warranting evaluation; however, the absence of eardrum rupture does not exclude the person from being at risk of other PBI [13,14,99,101]. A study of 647 terrorist bombing survivors showed that all casualties with BLIs had a fully developed clinical picture in the first hour after admission 
and that intestinal blast injury were rare and typically associated with other severe injuries [13]. Secondary blast injuries (SBI) occur when objects accelerated by the energy of the explosion strike a victim, often causing the most numerous injuries from blunt or penetrating ballistic trauma $[14,15,17]$. Tertiary blast injuries (TBI) can be viewed as the converse of SBI; the missile is stationary and the victim is propelled by expanding gases from high winds, resulting in a high incidence of blunt trauma from tumbling and impacting objects $[15,98]$. Quaternary injuries often imply injuries due to delayed causes such as crush injuries from building collapse or inhalation and burns from secondary fires $[27,47,75,78]$. Due to several injury mechanisms, explosions can cause a multiplicity and variety of injuries to several regions of the body in a single individual, referred to as a multi-dimensional injury $[68,82,84,91,102]$.

The anatomic site and nature of injury constitute some important prognostic factors among bombing victims [9]. Traumatic amputation of limbs caused by bomb blast carries a high mortality and thus has often been seen as an indication of fatality $[37,80]$. However, in the 2005 London bombings, nearly one-fourth (24.5\%) of those with traumatic amputations survived [80]. Thus, it has been held that blast injuries associated with late death such as primary limb amputation, open-long bone fractures, abdominal injuries, chest injuries, and blast lung injury, should instead be given priority in triage $[9,97]$. During the chaotic circumstances after an attack, it may be difficult for EMS to determine levels of consciousness and signs of life such as pulse and blood pressure. Almogy et al. [77] therefore proposed some easily recognizable external signs of trauma after bombings, to ease triage of BLI and to help EMS distinguish salvageable from non-salvageable casualties. From their study of 15 suicide bombings, they found that patients with skull fractures, burns covering more than $10 \%$ of the body surface area (BSA), and penetrating wounds to the head and torso, were more likely to suffer from BLI and require advanced trauma care. The presence of amputations, open fractures, and burns (covering more than $30 \%$ of BSA) was significantly higher in fatally injured people. If combined with no sign of life, these should be categorized as "unsalvageable", according to Almogy et al. [77]. Almogy et al. later showed that casualties with penetrating head injuries and those with more than 4 body areas injured were significantly more likely to suffer from BLI. As for intra-abdominal injuries, they were more likely in casualties with penetrating torso injuries and those with more than 4 body areas injured. Based on this, they moved to simplify EMS triage further by focusing on vital signs and the number of regions injured, where more than 4 injured body regions implied transfer to a Level I trauma center [103].

\subsubsection{Setting up Field Hospitals \& Personnel Matters}

There are two main approaches to providing prehospital care to trauma victims: Basic Life Support (BLS) treatment and rapid evacuation techniques (formerly referred to as
"Scoop and Run"); and Advanced Life Support (ALS) on scene, prior to transport (formerly referred to as "Stay and Play") [104]. The choice of whether to give advanced treatment on site and establish collections points versus quickly transferring patients to hospitals is based on the prevailing conditions, mostly affected by proximity to hospitals and the availability of transportation. Generally, this means that the ALS is recommended in rural areas while the BLS is executed in urban areas [7]. It has repeatedly been observed that by the time medical staff from the hospitals are at their highest number at the scene and assembly points have been established, the most seriously injured have already been transported to the hospitals [66]. According to Kluger [84], definitive care by well-trained physicians in wellequipped facilities has a higher impact on patient outcome than care on scene. Setting up field hospitals and sending mobile teams from hospitals to provide advanced treatment on scene is an alternative when there is not enough prehospital staff, when casualties are trapped, when appropriate hospitals are far away, or where limited transport facilities cause a delay in evacuation $[53,68,82,105]$. There have also been instances were physicians have been beneficial on the scene by enabling extrication and transfer to hospital, sometimes through field amputations [55,58,61]. Mostly though, researchers $[31,55,57]$ have concluded that physicians and nurses are not suitable for incident sites if they are untrained and unprepared to work in a suboptimal and dangerous prehospital environment because the risk to them is big, while the benefits are small. To provide meaningful assistance at the scene, personnel ought to be trained, organized, and have clear assignments in order to understand the workings of emergency services and be familiar with the pre-hospital environment $[41,44,46,60]$. The expertise of physicians and nurses may be of better use at the hospital, as individuals perform best when executing an extension of their normal work, where facilities and equipment are familiar $[38,57,87]$. The importance of training prehospital responders in the specifics of antagonistic attacks and general $\mathrm{MCl}$ management has also been highlighted to assure that they work with adapted procedures for mass casualties and have knowledge in management of blast injuries [53].

Several incidents have amounted to large groups of self-deployed medically trained "freelancers" and other volunteers; people approaching the scene or hospitals on their own initiative $[39,44,46,48,55,62,83,106]$. This has sometimes been discouraged and at other times encouraged, highlighting the importance of incorporating bystander response in response plans and training [20,29,57]. In Israel, educated and trained lay bystanders are considered frontline first responders and constitute a cornerstone in the defense measures against terrorism [20]. While meaning well, several examples exist where aid provided by volunteers has not been helpful $[46,49,50,55]$. Other accounts however, highlight beneficial actions, such as application of improvised tourniquets, carrying of stretchers, work at formalized triage and treatment stations in safe areas, and provision of evacuation of injured [27,32,43,49,50,53,61,71]. 


\subsubsection{Determining Ambition for Level of Care \& Treatment}

Treatment on site is best when focused on life-saving procedures while enabling evacuation [34]; Frykberg [9] concluded that a short interval between injury and treatment, and early aggressive resuscitation, constitute a prognostic factor for survival. It is imperative that medical staff check their instincts to deliver as much care as needed to each victim while in a mass casualty setting $[32,49]$. Instead, triage and treatment in MCAs often necessitate a battlefield mentality, using damage-control principles where minimally required care is provided to the maximum number of injuredwith consideration to available resources and personnel, on scene, and in receiving institutions $[6,8]$. Field personnel are challenged with identifying salvageable casualties in order to treat them sufficiently so that they reach the hospital alive $[6,32,37]$.

According to TCCC guidelines, control of external hemorrhage is placed ahead of airway control, exchanging the traditional $\mathrm{ABC}$ mnemonic (for airway, breathing, circulation) with MARCH: Massive Hemorrhage Control/Airway Support/Respiratory Threats/Circulation/Hypothermia [29]. However, the extent of treatment, and what procedures should be carried out in the area of explosion or shooting, is incongruent or unclearly described in the included studies. Some hold that external hemorrhage control should be the only procedure conducted before casualties are taken to a designated safe zone $[5,70]$. Others, hold that initial on-scene treatment should follow fundamental resuscitation protocols including spinal immobilization (c-spine), opening of obstructed airway (chin-lift maneuver), and control of breathing, while all other treatments are deferred to the next survey [32,34,47]. The main thing is that a minimum of emergency forces provide a minimum of procedures on an unsecure site, holding off the majority of staff and treatment on scene at established safe areas. With regard to field medical care, Stein and Hirshberg [99] concluded that airway with C-spine had probably saved the most salvageable casualties after terrorist explosions. Oxygenation may be monitored using pulse oximetry and, if necessary, improved by oxygen via mask and a rebreathing reservoir $[47,99]$. Needle insertion to relieve pneumothoraces may also be prudent $[37,47,99]$, and tracheal intubation may be performed if the patient's pulmonary status deteriorates $[34,47]$. Treatment of air embolism is supported by placing the casualty in the Trendelenburg and left-lateral-decubitus position [47]. Alignment and stabilization of fractures is another important treatment in the field. Covering open wounds, where possible, is also helpful/desirable $[47,99]$. Limbs that have experienced crush injuries may need to be splinted, and at an early stage severe crush injuries may be treated with IV fluids to help minimize the complications from rhabdomyolysis [47]. One important cause of coagulopathy in trauma patients is hypothermia, the risk for which may be reduced by covering wounds [34] and generally protecting casualties from the elements. Burns ought to be covered with a clean dressing, and IV fluids should be started for burns covering large BSA [47]. The Modified Brooke formula may be better for the management of burns as the use of Parklands formula, in addition to overestimation of burnt BSA, can cause overresuscitation [71]. The air-medical evacuation of bombing casualties from Bali to Australia demonstrated the risk of gradual deterioration in casualties with burns, threatening limbs which were previously well perfused which underlines the need for continuous assessment [85]. If amputations have occurred, the patient's limb should be covered, hemorrhage controlled and the amputated body part salvaged, covered, and transported to the hospital with the patient. Completion of partial amputations is not advised when in the field [47].

While use of tourniquets in military trauma is well established, their use in civilian practice has been more controversial $[34,80,107]$. While some accentuate the time-critical situation for casualties with exsanguinating hemorrhage [29], others hold that in the case of terrorist bombings these usually occur in urban settings with short evacuation times where plenty of volunteers are available to apply direct pressure [34]. However, providing speedy application of tourniquet to control bleeding in hemorrhaging casualties is encouraged in several articles to improve survival in MCAs $[5,29,56]$. In a civilian prehospital response, recommended interventions to severe bleedings thus include application of tourniquet to control extremity hemorrhage, hemostatic dressings to control bleeding from sites not amenable to a tourniquet, and "Sit up and lean forward" posture for casualties with direct maxillofacial trauma (which can result in either airway obstruction or bleeding into the airway) [29]. Support for tourniquet use was indicted in a study from the response to the 2005 London bombings as all the patients with amputations, except one, who were admitted to the Royal London Hospital, with makeshift tourniquets, survived their injuries while the one with no tourniquet did not [80]. Risks with improvised tourniquets however, also have been seen, e.g. after the Boston Marathon bombing. Several of the improvised tourniquets proved to be venous tourniquets, non-hemostatic and with paradoxical bleeding upon ED arrival [107]. In order to avoid unnecessary complications, a tourniquet should be able to "completely occlude arterial blood flow, have ease and speed of application under tactical situations and in the dark, be removable, portable, durable, inexpensive and cause minimal tissue necrosis and pain" [34]. Ideally, the tourniquet should be removed as soon as possible after application [34], meaning that it is important to document time of application. Direct pressure can also be used to control bleeding from external bleeding sites by applying consistent and significant pressure to the packed wound, with the injured person placed on a firm surface. In severe bleedings, direct pressure must be sustained until the person reaches the operating room [29], a procedure which may not be feasible in an MCA setting [34].

\subsubsection{Providing Psychological Support}

While this review is not focused on long-term psychological effects of terrorist attacks, some aspects relevant for on-scene care will confer terrorism as a "perfect traumatic stressor combining elements of malevolent intent, actual or 
threatened extreme harm, and unending fear of the future" [108]. Despite this, most people will recover without significant psychiatric sequelae although transient symptoms of stress are common after experiences of mass violence [36]. Early mental health assessment and intervention does not focus on providing "psychological forms of treatment" but rather down-to-earth and practical provision of basic services $[36,88]$. After large-scale trauma most psychological care is physical and includes establishing safety, providing food, shelter and medical assistance, mental health triage, and orientation with local services and information $[36,88]$. Psychological first aid also entails reducing psychological arousal, mobilizing support for those most distressed, keeping families together, and facilitating reunions with loved ones [36]. Providing information about community services, that the victim can access later, and describing upcoming steps in the criminal investigation and legal proceeding is also important [109]. Once mass terror survivors feel they are out of immediate danger and their basic needs have been met, they usually want answers; a shortage of accurate information is potentially traumatic and harmful if wild rumors result in panic or deprivation of services [88]. Response to a terrorist attack also requires a practical task of the responder: to obtain information from the victim in order to maximize the possibility of apprehending the perpetrator(s), prevent further violence, and plan for aiding other potential victims [88]. Responders are in a unique position to help victims deal with the impact of their ordeal by helping them restore a sense of safety and control, e.g. by providing a safe and quiet location in which they can treat and interview them [109]. Collaborating with mental health clinicians may be useful in such situations to help balance concerns for victim welfare and the need to obtain detailed information. Integrating them into responses to MCAs could therefore prove wise during pre-event planning $[36,88]$. It has been indicated that people who can contribute to the rescue in some way manage better as they do not feel helpless, they gain a measure of control [36]. Exemplified "buddy aid" approaches in some responses, where those triaged with minor injuries are encouraged to assist [50], may be one way to achieve this. In the case of bombings, it should be noted that victims suffering from primary blast injuries may fare poorly by strenuous physical activities, EMS personnel therefore need to reduce the activity level of potential blast-exposed individuals [15]. Planning has been highlighted as an area of response in need of improvement, in relation to psychological assistance $[7,30,110]$. Lacking command and coordination of the mental health responder group has led some receivers of aid to experience being "killed with kindness"; they are overwhelmed with offers of support and services [67].

\subsubsection{Caring for the Pediatric Casualty}

In addition to EMS personnel worldwide being less experienced, in dealing with emergency management of critically ill children compared to adults, pediatric victims of terrorist attacks suffer injuries not usually seen in the age group [19]. Waisman et al. [18] describe an experience-based development of a pediatric triage algorithm with changes to the performance of triage in children due to the difficulties and time-consuming practice, of obtaining measurements of vital signs and blood pressure in children, and due to different mechanisms of injury in children because of their physiological and anatomical characteristics. For further details please see original references $[18,19]$. Since children have unique characteristics and pediatric mass-casualty incidents are rare, prehospital personnel may have difficulties performing certain clinical procedures such as intubation or establishing an intravenous line. It has therefore been recommended that only simple life-saving procedures such as opening an airway or maintaining ventilation should be performed for children at the scene of an MCA. Other procedures should be postponed until the child's arrival to the ED. Optimally, children should be evacuated to a hospital with pediatric capabilities, but if they have critical injuries they may need to be stabilized at the nearest hospital first. If possible, it is also advisable that EMS staff find a familiar adult to keep the child company to the hospital during such a stressful event, but not if it results in significant delay in patient evacuation [19]. Emotional trauma, e.g., due to separation from parents, is a critical factor during pediatric care, which implies that it is vital to identify children assigned to the "delayed care" category with anxiety and acute emotional stress and provide them with psychosocial support [18]. Letting children help with small maneuvers, like undressing to allow examination, may be helpful for restoring their sense of control in an otherwise disorienting situation [88]. If the weather is cold or if children have to be undressed for decontamination or triage, responders have to consider that they are more susceptible to hypothermia [18].

\subsection{Transport}

Three major types of challenges to evacuation were exemplified in the articles reviewed, most of which coincide with unintentional mass-casualty incidents.

\subsubsection{Accessing \& Leaving the Scene}

Maintaining clearly identified, physical pathways for entry and exit from the scene is essential in order to ensure rapid and appropriate evacuation, as well as coordinated and controlled access $[2,20]$. Blockades by debris, underground location, or access through narrow streets have repeatedly made access difficult, resulting in dispersion of casualties to multiple collection points and prolonged evacuation time $[2,28,30,33,60]$. Multiple access or unclear designation routes have caused problems, not just for evacuation but also initial command, communication, and cooperation between units $[2,30]$. Multiple exit points for those wounded of varying severity and lack of coordination among the rescue teams have also led medical teams to miss groups of casualties, delaying their care [2].

Road congestion has made it difficult to get both to and 
from the scene [39,64], occasionally exacerbated by rescue service, security, or police forces blocking entrance of EMS to the scene $[2,33,59]$ and other times alleviated through police establishment of designated evacuation routes to the hospitals $[32,46,63,68]$. Targeting public transportation infrastructure, like subways and buses, can aggravate obstructions to medical evacuation, preventing medical staff from reaching their post and discharged patients from clearing the hospital $[60,111]$. Ways to adapt to road congestion include pre-planned deployment of paramedics on bicycles; using helicopters to move doctors, equipment, and casualties; and sending nurses onto main roads to triage people seeking medical care $[60,63,69]$.

The topographical location has been known to create access difficulties both for road-bound vehicles and helicopters [70]. Such accessibility difficulties may result in inefficient convergence of ambulances on the incident scene, forcing them to wait in queue at a distance from the scene [112], and creating a more physically taxing rescue effort. Use of all-terrain vehicles have been beneficial for transportation in cumbersome terrain [50].

\subsubsection{Evacuating from Urban or Rural Scenes}

A determinant of mortality among victims of antagonistic attacks is the availability of medical resources at the scene and the prehospital system of transport and care. Longer times for rescue and transport to definitive care, from isolated areas, tends to result in higher mortality rates [9]. The distance to definitive care and available means of transportation, from urban or rural incident scenes, require different approaches in terms of the degree of prehospital care on site versus transfer and care at an appropriate medical facility. Pinkert et al. [95] concluded, that when an MCA affects an urban area, in the vicinity of several hospitals, the best course of action involved rapid arrival of a large number of ambulances, rapid primary triage, use of evacuation priorities, and rapid distribution of casualties among all nearby hospitals in the area. Such a response requires synchronization of the EMS response and appropriate distribution of casualties to hospitals [64,95]. As most attacks occur in an urban setting [34], rapid evacuation will be suitable in most cases, but when attacks occur in rural areas, there may be limited EMS and small, local hospitals with fewer resources, and limited abilities to cope with a large number of injured people [106]. Such responses may require the use of other modes of transportation for medical evacuation, transfer of staff and equipment, higher degrees of treatment on site, or use of local hospitals as casualty collection points, dependent on their capabilities.

Helicopters and fixed-wing aircrafts have been essential to deploy staff and equipment to the site or primary receiving hospitals $[44,93,105,112]$, as well as use for primary or secondary evacuation and distribution of injured $[93,105,112]$. Improvements in air evacuation have significantly upgraded the ability of the EMS to rapidly evacuate MCA casualties in distant areas to tertiary care facilities, but effective use of air-medical evacuation requires planning, coordination, and training [112]. It is also a mode of transportation sensitive to the weather conditions, thus not necessarily serviceable when needed [92]. Coordination of helicopters have been challenging due to poor weather conditions, uncontrolled airspace, unsettled safety settings, and unsuitable placement of casualty clearing stations [41]. To facilitate air-medical evacuation, incident command ought to gather and transmit information regarding landing zone characteristics and severity of injuries prior to reaching the site, possibly by assigning an Air Support Manager [112]. While air-medical evacuation can be a suitable option for incidents at sea, it may also entail difficulties depending on the vessel's size: there is not always space to land and the use of a rescue hoist is time consuming. Winds from rotors risk blowing away equipment not lashed, impacting the care of those on scene [35]. Some medically challenging conditions and treatments described in connection to air-medical evacuation of blast and burn casualties include underappreciated hypoxemia; unrecognized pneumothorax or arterial air-embolism [15]; stabilizing fractures, [102]; maintaining normothermia $[20,27]$ and providing correct amounts of fluid replacement to avoid swelling of the airway [27].

\subsubsection{Distributing Casualties}

Like other mass-casualty incidents, distribution of casualties to appropriate health care facilities is one of the most important issues after MCAs [104], as bed availability, capability to manage specific injuries, and potential for casualty transfer is vital to ensure good patient care [4]. Distribution of casualties however, has been problematic after several MCAs $[2,17,28,64]$. Optimal distribution of casualties is hinged upon well-established local command and communications with the receiving hospitals, facilitated through preparation [6]. From two MCAs, Rodoplu et al. [17,28] found that maldistribution seemed associated with distance from the scene, type of medical facility, personal preference of survivors, lack of central coordination of ambulances, and lack of field triage.

A common issue after urban MCAs has been the hospital nearest to the site becoming overwhelmed [20,30,58,94]. This is largely due to the common phenomena known as self-evacuation or self-triage, where people with minor injuries make their own way to the hospital [29,59,84], aided by non-medical vehicles $[27,30,61,65,66,72,86,94$, 113]. This results in an early arrival pattern of mild casualties who can be treated and released, while ambulances carrying the more severely injured and casualties requiring extrication arrive later $[15,32,43,62,86,94]$. Similar patterns may also arise if minor injured people are assembled and transferred to the hospital by bus, as this can be achieved more quickly than the medical evacuation of more severely injured people [64]. If evacuation of minor injured people is controlled, it is more suitable to evacuate them to a more distant hospital, and if arrival of patients is not controlled and the hospital is overwhelmed, 
it may be necessary for it to function as a casualty collection point, triaging between high-acuity and low-acuity casualties, and secondarily transporting some to more distant facilities [47,111]. Despite the pattern of the closest hospital often being overwhelmed, recommendations and practice from several incidents have been to evacuate all patients with immediate, life-threatening injuries to the closest hospital for evaluation and stabilization [86,95,96,104]. Meanwhile, casualty-clearing stations may be used to treat those with minor injuries on site [66], providing Advanced Life Support (ALS) until they can be evacuated directly to a suitable facility [104].

Another approach $[86,106]$ is to evacuate all casualties to the hospital closest to the site for advanced, hospitalbased resuscitation. The principle of an evacuation hospital (or "triage hospital") has been recommended when the needs of the patients greatly outweigh the capabilities of the receiving hospital or when the expected number of patients amount to a continued patient flow. This sets the hospital to a mode of treating and discharging mild casualties while stabilizing, and secondarily evacuating, patients that require admission $[93,105]$.

\section{Concluding Discussion}

In this review of 105 articles regarding response challenges on scene of a mass-casualty attack, difficulties were found corresponding to each prioritized task, as defined in the MIMMS framework. Two aspects of importance, not equally highlighted in the original framework, were functional coordination and collaboration, as well as the influence of the environment. While the former has been noted in analysis of previous responses to unintentional incidents, the significance of setting, noted during scene assessment, is especially vital during bombings. It is not only vital in estimating the number of direct fatalities and injured, but also as an indicator for possible injuries and needs for equipment and specialist care. Besides issues related to the "assessment task", other specific challenges in MCA management, compared to unintentional incidents, were particularly clear in relation to safety, triage, and treatment. Meanwhile, problems related to command, coordination, and communication were the most commonly reported, showing the overlap in management of unintentional and intentional incidents. Hence, experience in dealing with unintentional incidents may prepare responders for challenges with command, coordination, and communication, whereas specific challenges with safety, assessment, triage, and treatment would remain foreign. Many of the included articles claim that preparedness for MCAs thus require planning and specific training $[5,6,32,52,60,71,90,95,96,104]$. It may be inferred that if inter-organizational collaboration is to be more offensive $[5,29,56]$, these preparatory efforts will be even more vital. In relation to preparatory efforts, Vidali and Hutchens [114] stressed that fragmentation between crisis management and public safety system actors often constitute a hindrance to readiness measurements and capability aggregation. They further highlight the need to distinguish between capacity (quantifiable assets such as equipment, vehicles and radios) and capability (qualitative measurements of e.g. skills, training and coordination). If the resources are to be ready for use, both aspects need to be accounted for, and failing to do so could amount to poor investment decisions. Examples of such investment were observed by López-Carresi [30] after the Madrid bombings, where the Madrid-based EMS decided to purchase more mobile telephones even though scarcity of transmission equipment had not been the cause of communication failures. Clearly, what is needed to increase preparedness depends on the context, but as López-Carresi pointed out, there is often a reluctance to make deep structural or system changes (which may be interpreted as criticism of the current system), as opposed to adjustments of the existing work schemes (which may be seen as previous lack of funding or other resources). Effectively increasing readiness for MCAs will thus likely entail struggles to overcome fragmentation between the police, rescue service, EMS and the broader crisis management system, as well as enabling critical and prestige-less assessments of needed preparatory efforts.

Regarding the strength of evidence of the management challenges, articles related to direct and indirect threats to safety on scene, [54] and issues concerning blast injuries with implications during assessment, triage, and treatment had higher scientific quality $[10,11,78,80,101]$. The scientific quality of the articles varied, partly due to the difficulties of studying an issue where circumstances and occurrence cannot be foretold or controlled (effecting study design). It was also partly due to the limitations of this study-as a result of the inclusion and exclusion criteria used to achieve the study's aim (effecting eligibility). If one were to search more databases, or additionally include studies based on simulations and relating to unintentional incidents, some findings may have been made more robust. In order to be feasible, one would have had to focus such a study on a specific prioritized task on scene and/or the perspective of only one responder group. This study instead lays the basis for such studies in the future and includes valuable issues of consideration for personnel within the EMS, police, and rescue service. The inclusion of articles of lower scientific quality and the breadth of the review may imply limitations for practical use. However, it is not meant as a guideline for how incident management should be conducted everywhere, since incident response needs to be adapted to local incident management systems, resources, and expectations. One cannot simply cut and paste a system onto another; however, reoccurring bottlenecks can be learned from other countries, and appropriate adjustments for dealing with such issues can be made in accordance with the structure of systems elsewhere [115]. 


\section{Acknowledgements}

$\mathrm{AH}$ conceptualized, designed the study, acquired the data, analyzed eligibility and quality of identified records, conducted the data extraction, and interpreted the data. She drafted and revised the manuscript after feedback by professors Ulf Björnstig and Britt-Inger Saveman, whom se- cured study funding from the Swedish National Board of Health and Welfare. The author is grateful for funding by the Swedish National Board of Health and Welfare. Critical readings of the manuscript by Professor Ulf Björnstig and Professor Britt-Inger Saveman were also appreciated. The author declares no competing interests.

\section{References and Notes}

[1] Holgersson A, Björnstig U. Mass-casualty attacks on public transportation. Journal of Transport Security. 2014;7:1-16. doi:10.1007/s12198-013-0125-z.

[2] Perliger A, Pedahzur A, Zalmanovitch Y. The Defensive Dimension of the Battle against Terrorism - An Analysis of Management of Terror Incidents in Jerusalem. Journal of Contingencies \& Crisis Management. 2005;13(2):79-91. doi:10.1111/j.14685973.2005.00460.x.

[3] Solheim T, Lorentsen M, Sundnes PK, Bang G, Bremnes L. The "Scandinavian Star" ferry disaster 1990-A challenge to forensic odontology. International Journal of Legal Medicine. 1992;104(6):339-345. doi:10.1007/bf01369554.

[4] Eckstein M, Cowen AR. Scene safety in the face of automatic weapons fire: A new dilemma for EMS? Prehospital Emergency Care. 1998;2(2):117-122. doi:10.1080/10903129808958854.

[5] Autrey AW, Hick JL, Bramer K, Berndt J, Bundt J. 3 Echo: Concept of Operations for Early Care and Evacuation of Victims of Mass Violence. Prehospital and Disaster Medicine. 2014;29(4):421-428. doi:10.1017/s1049023x14000557.

[6] Kashuk JL, Halperin P, Caspi G, Colwell C, Moore EE. Bomb Explosions in Acts of Terrorism: Evil Creativity Challenges Our Trauma Systems. Journal of the American College of Surgeons. 2009;209(1):134-140. doi:10.1016/j.jamcollsurg.2009.01.049.

[7] Bolling R, Ehrlin Y, Forsberg R, Rüter A, Soest V, Vikström T, et al. KAMEDO Report No. 90: Terrorist attacks in Madrid, Spain, 2004. Prehospital and Disaster Medicine. 2007;22(3):252-257. doi:10.1017/S1049023X00004775.

[8] Aylwin CJ, König TC, Brennan NW, Shirley PJ, Davies G, Walsh MS, et al. Reduction in critical mortality in urban mass casualty incidents: analysis of triage, surge, and resource use after the London bombings on July 7, 2005. The Lancet. 2006;368(9554):2219-2225. doi:10.1016/s0140-6736(06)69896-6.

[9] Frykberg ER. Medical Management of Disasters and Mass Casualties From Terrorist Bombings: How Can We Cope? The Journal of Trauma: Injury, Infection, and Critical Care. 2002;53(2):201-212. doi:10.1097/00005373-200208000-00001.

[10] Patel H, Dryden S, Gupta A, Stewart N. Human body projectiles implantation in victims of suicide bombings and implications for health and emergency care providers: the $7 / 7$ experience. The Annals of The Royal College of Surgeons of England. 2012;94(5):313-317. doi:10.1308/003588412x13171221591772.

[11] Morley MG, Nguyen JK, Heier JS, Shingleton BJ, Pasternak JF, Bower KS. Blast Eye Injuries: A Review for First Responders. Disaster Medicine and Public Health Preparedness. 2010;4(02):154-160. doi:10.1001/dmp.v4n2.hra10003.

[12] Katz E, Ofek B, Adler J, Abramowitz H, Krausz M. Primary Blast Injury After a Bomb Explosion in a Civilian Bus. Annals of Surgery. 1989;209(4):484-488. doi:10.1097/00000658-198904000-00016.

[13] Leibovici D, Gofrit ON, Shapira SC. Eardrum Perforation in Explosion Survivors: Is It a Marker of Pulmonary Blast Injury? Annals of Emergency Medicine. 1999;34(2):168-172. doi:10.1016/s01960644(99)70225-8.

[14] Hodgetts TJ. Lessons from the Musgrave Park Hospital bombing. Injury. 1993;24(4):219-221. doi:10.1016/0020-1383(93)90171-2.

[15] Wightman JM, Gladish SL. Explosions and blast injuries. Annals of Emergency Medicine. 2001;37(6):664-678. doi:10.1067/mem.2001.114906.
[16] Kosashvili Y, Loebenberg MI, Lin G, Peleg K, Zvi F, Kluger Y, et al. Medical consequences of suicide bombing mass casualty incidents: The impact of explosion setting on injury patterns. Injury. 2009;40(7):698-702. doi:10.1016/j.injury.2008.06.037.

[17] Rodoplu U. Impact of the Terrorist Bombings of the Neve Shalom and Beth Israel Synagogues on a Hospital in Istanbul, Turkey. Academic Emergency Medicine. 2005;12(2):135-141. doi:10.1197/j.aem.2004.09.019.

[18] Waisman $\mathrm{Y}$, Aharonson-Daniel L, Mor M, Amir L, Peleg K. The impact of terrorism on children: A two-year experience. Prehospital and Disaster Medicine. 2003;18(3)::242-248. doi:10.1017/S1049023X00001114.

[19] Waisman Y, Amir L, Mor M, Feigenberg Z, Aharonson LD, Peleg K, et al. Prehospital Response and Field Triage in Pediatric Mass Casualty Incidents: The Israeli Experience. Clinical Pediatric Emergency Medicine. 2006;7(1):52-58. doi:10.1016/j.cpem.2006.01.006.

[20] Lerner EB, O'Connor RE, Schwartz R, Brinsfield K, Ashkenazi I, Degutis LC, et al. Blast-Related Injuries from Terrorism: An International Perspective. Prehospital Emergency Care. 2007;11(2):137153. doi:10.1080/10903120701204714.

[21] Torraco RJ. Writing Integrative Literature Reviews: Guidelines and Examples. Human Resource Development Review. 2005;4(3):356367. doi: $10.1177 / 1534484305278283$.

[22] Evaluation of methods in public health and health care: A handbook Stockholm, Sweden: The Swedish State Advisory Committee on Assessment of Health Care Interventions; 2013.

[23] Type of Study. Introduction to Evidence-Based Practice;. Available from: http://guides.mclibrary.duke.edu/c.php?g=158201\&p= 1036068.

[24] Melnyk B, Fineout-Overholt E, editors. Evidence-based practice in nursing and healthcare: A guide to best practice. 2nd ed. Philadelphia, PA, USA: Lippincott Williams \& Wilkins; 2010.

[25] Hodgetts T, Mackaway-Jones K. Major incident medical management and support: The practical approach. London, UK: BMJ Publishing Group; 1995.

[26] Hodgetts T, Mackway-Jones K. [MIMMS- in Swedish! Major Incident Medical Management and Support, a methodological approach to manage major incidents]. Lund, Sweden: Studentlitteratur; 2004.

[27] Brolén $P$, Örtenwall $P$, Österhed $H$, Brändström $H$. KAMEDO Report No. 89: Terrorist attack in Bali, 2002. Prehospital and Disaster Medicine. 2007;22(3):246-250. doi:10.1017/S1049023X00004763.

[28] Rodoplu U, Arnold J, Tokyay R, Ersoy G, Cetiner S, Yücel T. Mass-casualty terrorist bombings in Istanbul, Turkey, November 2003: Report of the events and the prehospital emergency response. Prehospital and Disaster Medicine. 2004;19(2):133-145 doi:10.1017/S1049023X00001643.

[29] Jacobs L, Wade D, McSwain N, Butler F, Fabbri W, Eastman $A$, et al. Hartford Consensus: A Call to Action for THREAT, a Medical Disaster Preparedness Concept. Journal of the American College of Surgeons. 2014;218(3):467-475. doi:10.1016/j.jamcollsurg.2013.12.009.

[30] Carresi AL. The 2004 Madrid train bombings: an analysis of pre-hospital management. Disasters. 2007;32(1):41-65. doi:10.1111/j.1467-7717.2007.01026.x.

[31] Simon R, Teperman S. The World Trade Center Attack-Lessons for disaster management. Critical Care. 2001;5(6):318-320. doi:10.1186/cc1060.

[32] Singer AJ, Singer AH, Halperin P, Kaspi G, Assaf J. Medical lessons from terror attacks in Israel. The Journal of Emergency Medicine. 
2007;32(1):87-92. doi:10.1016/j.jemermed.2006.06.007.

[33] Perliger A, Pedahzur A. Coping with Suicide Attacks: Lessons from Israel. Public Money and Management. 2006;26(5):281-286. doi:10.1111/j.1467-9302.2006.00541.x.

[34] Almogy G, Rivkind Al. Terror in the 21st Century: Milestones and Prospects-Part II. Current Problems in Surgery. 2007;44(9):566619. doi:10.1067/j.cpsurg.2007.06.001.

[35] Glassberg E, Lipsky AM, Abramovich A, Sergeev I, Hochman O, Ash N. A dynamic mass casualty incident at sea. Journal of Trauma and Acute Care Surgery. 2013;75(2):292-297. doi:10.1097/ta.0b013e318294662d.

[36] Ritchie E. Mass Violence and Early Intervention: Best Practice Guidelines. Primary Psychiatry. 2003;10(8):43-48.

[37] Vassallo DJ, Graham PJK, Gupta G, Alempijevic D. "Bomb Explosion On The Nis Express" - Lessons From A Major Incident, Kosovo 16 Feb 2001. Journal of the Royal Army Medical Corps. 2005;151(1):19-29. doi:10.1136/jramc-151-01-04.

[38] Juffermans J, Bierens JJLM. Recurrent Medical Response Problems during Five Recent Disasters in the Netherlands. Prehospital and Disaster Medicine. 2010;25(02):127-136. doi:10.1017/s1049023x00007858.

[39] Pryor JP. The 2001 World Trade Center Disaster: Summary and Evaluation of Experiences. European Journal of Trauma and Emergency Surgery. 2009;35(3):212-224. doi:10.1007/s00068009-9902-6.

[40] Reissman DB, Howard J. Responder safety and health: Preparing for future disasters. Mount Sinai Journal of Medicine. 2008;75(2):135-141. doi:10.1002/msj.20024.

[41] Sollid SJ, Rimstad R, Rehn M, Nakstad AR, Tomlinson AE, Strand T, et al. Oslo government district bombing and Utøya island shooting July 22, 2011: The immediate prehospital emergency medical service response. Scandinavian Journal of Trauma, Resuscitation and Emergency Medicine. 2012;20(1):3. doi:10.1186/1757-7241-20-3.

[42] Wang D, Sava J, Sample G, Jordan M. The Pentagon and 9/11. Critical Care Medicine. 2005;33(1 (suppl.)):s42-s47. doi:10.1097/01.CCM.0000151066.06423.33.

[43] Bland S. HEMS training and the 7th July 2005: A personal perspective. Journal of the Royal Naval Medical Service. 2006;92(3):130135.

[44] Lockey DJ, MacKenzie R, Redhead J, Wise D, Harris T, Weaver A, et al. London bombings July 2005: The immediate prehospital medical response. Resuscitation. 2005;66(2):ix-xii. doi:10.1016/j.resuscitation.2005.07.005

[45] Spadafora R. Firefighter safety and health issues at the World Trade Center site. American Journal of Industrial Medicine. 2002 nov;42(6):532-538. doi:10.1002/ajim.10153.

[46] Larson RC, Metzger MD, Cahn MF. Responding to Emergencies: Lessons Learned and the Need for Analysis. Interfaces. 2006;36(6):486-501. doi:10.1287/inte.1060.0250.

[47] Kapur B, Pillow T, Nemeth I. Prehospital care algorithm for blast injuries due to bombing incidents. Prehospital and Disaster Medicine. 2010;25(6):595-600. doi:10.1017/S1049023X00008815.

[48] Bradt DA. Site Management of Health Issues in the 2001 World Trade Center Disaster. Academic Emergency Medicine. 2003;10(6):650-660. doi:10.1197/aemj.10.6.650.

[49] Martinez C, Gonzalez D. The World Trade Center Attack-Doctors in the fire and police services. Critical Care. 2001;5(6):304-306. doi:10.1186/cc1055

[50] Cook L. The World Trade Center Attack-The paramedic response: An insider's view. Crit Care. 2001;5(6):301-303. doi:10.1186/cc1054

[51] Roy N, Kapil V, Subbarao I, Ashkenazi I. Mass Casualty Response in the 2008 Mumbai Terrorist Attacks. Disaster Medicine and Public Health Preparedness. 2011;5(04):273-279. doi:10.1001/dmp.2011.80.

[52] Calland V. A brief overview of personal safety at incident sites. Emergency Medicine Journal. 2006;23(11):878-882. doi:10.1136/emj.2004.022624.

[53] Deverell E, Örtenwall P, Almgren O, Riddez L. KAMEDO report no. 87: Bomb attack in Finnish Shopping Center, 2002. Prehosp Disaster Med. 2007;22(1):86-88. doi:10.1017/S1049023X00004404.

[54] Thompson J, Rehn M, Lossius HM, Lockey D. Risks to emergency medical responders at terrorist incidents: a narrative review of the medical literature. Critical Care. 2014;18(5). doi:10.1186/s13054 014-0521-1.

[55] Cushman J, Pachter L, Beaton H. Two New York City Hospitals' Surgical Response to the September 11, 2001, Terrorist Attack on New York City. J Trauma. 2003;54(1):147-155 doi:10.1097/01.TA.0000046311.11766.27.

[56] Jacobs LM, Wade D, McSwain NE, Butler FK, Fabbri W, Eastman A, et al. Hartford Consensus: A Call to Action for THREAT, a Medical Disaster Preparedness Concept. Journal of the American College of Surgeons. 2014;218(3):467-475 doi:10.1016/j.jamcollsurg.2013.12.009.

[57] Steedman DJ, Gordon MWG, Cusack S, White M, Robertson CE, Little K. Lessons for mobile medical teams following the Lockerbie and Guthrie Street disasters. Injury. 1991;22(3):215218. doi:10.1016/0020-1383(91)90044-f.

[58] Teague DC. Mass Casualties in the Oklahoma City Bombing. Clinical Orthopaedics and Related Research. 2004;422:77-81. doi:10.1097/01.blo.0000131201.20418.82.

[59] Brown MG, Marshall SG. The Enniskillen bomb: a disaster plan. British Medical Journal. 1988;297(6656):1113-1116. doi:10.1136/bmj.297.6656.1113.

[60] Ryan J, Montgomery H. Terrorism and the Medical Response. New England Journal of Medicine. 2005;353(6):543-545. doi:10.1056/NEJMp058177.

[61] Maningas P, Robinson M, Mallonee S. The EMS response to the Oklahoma City bombing. Prehospital and Disaster Medicine. 1997;12(2):80-85. doi:10.1017/S1049023X0003733X.

[62] Lavery G, Horan E. Clinical review: Communication and logistics in the response to the 1998 terrorist bombings in Omagh, Northern Ireland. Critical Care. 2005;9:401-408. doi:10.1186/cc3502.

[63] Jurkovich T. September 11th-the Pentagon disaster. Critical Care Nursing Clinics of North America. 2003;15(2):143-148. doi:10.1016/s0899-5885(02)00072-2.

[64] Raiter Y, Farfel A, Lehavi O, Goren OB, Shamiss A, Priel Z, et al. Mass casualty incident management, triage, injury distribution of casualties and rate of arrival of casualties at the hospitals: Lessons from a suicide bomber attack in downtown Tel Aviv. Emergency Medicine Journal. 2008;25(4):225-229. doi:10.1136/emj.2007.052399.

[65] Wild J, Maher J, Frazee RC, Craun ML, Davis ML, Childs EW, et al. The Fort Hood Massacre. Journal of Trauma and Acute Care Surgery. 2012;72(6):1709-1713 doi:10.1097/ta.0b013e318250cd10.

[66] Waage A, Hamberger B, Lundin T, Suserud BO, Riddez L. KAMEDO report no. 84: Terrorist attacks against the World Trade Center, 11, Septerber 2001. Prehospital and Disaster Medicine. 2006;21(2):129-131. doi:10.1017/S1049023X00003526.

[67] Cozza S, Huleatt W, James L. Walter Reed Army Medical Center's mental health response to the Pentagon attack. Military Medicine 2002;167(Suppl. 4):12-16.

[68] Tucker K, Lettin A. The Tower of London bomb explosion. British Medicine Journal. 1975;3(5978):287-290. doi:10.1136/bmj.3.5978.287.

[69] Redhead J, Ward P, Batrick N. The London attacks-Response: Prehospital and hospital care. New England Journal of Medicine. 2005;353(6):546-547. doi:10.1056/NEJMp058178.

[70] Leiba A, Schwartz D, Eran T, Blumenfeld A, Laor D, Goldberg A, et al DISAST-CIR: Disastrous Incidents Systematic Analysis Through Components, Interactions and Results: Application to a Large-Scale Train Accident. The Journal of Emergency Medicine. 2009;37(1):4650. doi:10.1016/j.jemermed.2007.09.025.

[71] Mozingo DW, Barillo DJ, Holcomb JB. The Pope Air Force Base Aircraft Crash and Burn Disaster. Journal of Burn Care \& Rehabilitation 2005;26(2):132-140. doi:10.1097/01.bcr.0000155536.98314.d8.

[72] Leiba A, Halpern P, Priel IE, Shamiss A, Koren I, Kotler D, et al. A Terrorist Suicide Bombing at a Nightclub in Tel Aviv: Analyzing Response to a Nighttime, Weekend, Multi-Casualty Incident. Journal of Emergency Nursing. 2006;32(4):294-298. doi:10.1016/j.jen.2006.03.018.

[73] Almogy G, Belzberg H, Mintz Y, Pikarsky AK, Zamir G, Rivkind AI. Suicide Bombing Attacks. Annals of Surgery. 2004;239(3):295-303. 
doi:10.1097/01.sla.0000114014.63423.55.

[74] Lee C, Davis T, Noji E. Suicide bombing of the Mineralnye Vody train: case study in using open-source information for open-source health intelligence. Prehospital and Disaster Medicine. 2007;22(4):276280. doi:10.1017/S1049023X00004866.

[75] Morley B, Leslie GD. Terrorist bombings: Motives, methods and patterns of injuries. Australasian Emergency Nursing Journal. 2007;10(1):5-12. doi:10.1016/j.aenj.2006.07.001.

[76] Adler J, Golan E, Golan J, Yitzhaki M, Ben-Hur N. Terrorist bombing experience during 1975-1979: casualties admitted to the Shaare Zedeh medical center. Israel Journal of Medical Sciences. 1983;19(2):189-193.

[77] Almogy G. Can External Signs of Trauma Guide Management? Archives of Surgery. 2005;140(4):390. doi:10.1001/archsurg.140.4.390.

[78] Arnold JL, Halpern P, Tsai MC, Smithline H. Mass casualty terrorist bombings. Annals of Emergency Medicine. 2004;43(2):263-273. doi:10.1016/s0196-0644(03)00723-6.

[79] Leibovici D, Gofrit ON, Stein M, Shapira SC, Noga Y, Heruti RJ, et al. Blast Injuries. The Journal of Trauma. 1996;41(6):1030-1035. doi:10.1097/00005373-199612000-00015.

[80] Patel HDL, Dryden S, Gupta A, Ang SC. Pattern and mechanism of traumatic limb amputations after explosive blast. Journal of Trauma and Acute Care Surgery. 2012;73(3):784. doi:10.1097/ta.0b013e318265e984

[81] Mallonee S. Physical injuries and fatalities resulting from the Oklahoma City bombing. Journal of the American Medical Association. 1996;276(5):382-387. doi:10.1001/jama.276.5.382.

[82] Brismar B, Bergenwald L. The Terrorist Bomb Explosion in Bologna, Italy, 1980. The Journal of Trauma. 1982;22(3):216-220. doi:10.1097/00005373-198203000-00007.

[83] Dellinger AM, Waxweiler RJ, Mallonee S. Injuries to rescue workers following the Oklahoma City bombing. American Journal of Industrial Medicine. 1997;31(6):727-732. doi:10.1002/(SICI)10970274(199706)31:6;727::AID-AJIM9;3.0.CO;2-N.

[84] Kashuk JL, Halperin P, Caspi G, Colwell C, Moore EE. Bomb Explosions in Acts of Terrorism: Evil Creativity Challenges Our Trauma Systems. Journal of the American College of Surgeons. 2009;209(1):134-140. doi:10.1016/j.jamcollsurg.2009.01.049.

[85] Read D, Ashford B. Surgical aspects of operation Bali assist: initial wound surgery on the tarmac and in flight. ANZ J Surg. 2004;74(11):986-991. doi:10.1111/j.1445-1433.2004.03246.x.

[86] Schwartz D, Pinkert M, Leiba A, Oren M, Haspel J, Levi Y, et al. Significance of a Level-2, "selective secondary evacuation" hospital during a peripheral town terrorist attack. Prehospital and Disaster Medicine. 2007;22(1):59-66. doi:10.1017/S1049023X00004350.

[87] Waage S, Poole JC, Thorgersen EB. Rural hospital mass casualty response to a terrorist shooting spree. British Journal of Surgery. 2013;100(9):1198-1204. doi:10.1002/bjs.9203.

[88] Miller L. Psychological interventions for terroristic trauma: Symptoms, syndromes, and treatment strategies. Psychotherapy. 2002;39(4):283-296. doi:10.1037/0033-3204.39.4.283.

[89] Bloch Y, Leiba A, Veacnin N, Paizer Y, Schwartz D, Kraskas A, et al. Managing Mild Casualties in Mass-Casualty Incidents: Lessons Leaarned from an Aborted Terrorist Attack. Prehosp Disaster Med. 2007;22(3):181-185. doi:10.1017/S1049023X00004623.

[90] Feliciano D, Anderson G, Rozycki G, Ingram W, Ansley J, Namias N, et al. Management of casualties from the bombing at the Centennial Olympics. The American Journal of Surgery. 1998;176(6):538-543. doi:10.1016/s0002-9610(98)00263-3.

[91] Rignault D, Deligny M. The 1986 Terrorist Bombing Experience in Paris. Annals of Surgery. 1989;209(3):368-373. doi:10.1097/00000658-198903000-00019.

[92] Kaplowitz L, Reece M, Hershey JH, Gilbert CM, Subbarao I. Regional Health System Response to the Virginia Tech Mass Casualty Incident. Disaster Medicine and Public Health Preparedness. 2007;1(S1):S9-S13. doi:10.1097/dmp.0b013e318149f5a2.

[93] Leiba A, Blumenfeld A, Hourvitz A, Weiss G, Peres M, Laor D, et al. Lessons learned from cross-border medical response to the terrorist bombings in Tabba and Ras-el-Satan, Egypt on 07 October 2004. Prehospital and Disaster Medicine. 2005;20(4):253-257. doi:10.1017/S1049023X00002624.
[94] Hogan DE, Waeckerle JF, Dire DJ, Lillibridge SR. Emergency Department Impact of the Oklahoma City Terrorist Bombing. Annals of Emergency Medicine. 1999;34(2):160-167. doi:10.1016/s01960644(99)70224-6.

[95] Pinkert M, Lehavi O, Benin Goren O, Raiter Y, Shamis A, Schwartz $D$, et al. Primary triage, evacuation priorities, and rapid primary dis tribution between adjacent hospitals-Lessons learned from a suicide bomber attack in downtown Tel-Aviv. Prehospital and Disaster Medicine. 2008;23(4):337-341. doi:10.1017/S1049023X00005975

[96] Einav S, Feigenberg Z, Weissman C, Zaichik D, Caspi G Kotler D, et al. Evacuation Priorities in Mass Casualty TerrorRelated Events. Annals of Surgery. 2004;239(3):304-310. doi:10.1097/01.sla.0000114013.19114.57.

[97] Langworthy MJ, Sabra J, Gould M. Terrorism and Blast Phenomena. Clinical Orthopaedics and Related Research. 2004;422:82-87. doi:10.1097/01.blo.0000128293.43913.ca.

[98] Page P. Trauma and terror-Suicide bombs and their medical management. Trauma. 2010;13(1):17-21. doi:10.1177/1460408610384027.

[99] Stein M, Hirshberg A. Medical Consequences of Terrorism: The Conventional Weapon Threat. Surgical Clinics of North America. 1999;79(6):1537-1552. doi:10.1016/S0039-6109(05)70091-8.

[100] Goh S. Bomb blast mass casualty incidents: Initial triage and management of injuries. Singapore Med J. 2009;50(1):101-106.

[101] Radford P, Patel HDL, Hamilton N, Collins M, Dryden S. Tympanic Membrane Rupture in the Survivors of the July 7, 2005, London Bombings. Otolaryngology - Head and Neck Surgery. 2011;145(5):806-812. doi:10.1177/0194599811411143.

[102] Davis TP, Alexander BA, Lambert EW, Simpson RB, Unger DV, Lee $\mathrm{J}$, et al. Distribution and Care of Shipboard Blast Injuries (USS Cole DDG-67). The Journal of Trauma: Injury, Infection, and Critical Care. 2003;55(6):1022-1028. doi:10.1097/01.ta.0000100837.38530.d1.

[103] Muggia-Sullam M. Suicide Bombing Attacks: Can External Signs Predict Internal Injuries? Annals of Surgery. 2007;245(3):502 doi:10.1097/01.sla.0000256107.84051.23.

[104] Adini B, Cohen R, Glassberg E, Azaria B, Simon D, Stein M, et al. Reconsidering Policy of Casualty Evacuation in a Remote Mass-Casualty Incident. Prehospital and Disaster Medicine. 2013;29(01):91-95. doi:10.1017/s1049023×13008935.

[105] Karp E, Sebbag G, Peiser J, Dukhno O, Ovnat A, Levy I, et al. Mass casualty incident after the Taba terrorist attack: an organisational and medical challenge. Disasters. 2007;31(1):104-112. doi:10.1111/j.1467-7717.2007.00343.x.

[106] Bloch Y, Schwartz D, Pinkert M, Blumenfeld A, Avinoam S, Hevion $G$, et al. Distribution of casualties in a mass casualty incident with three local hopitals in the periphery of a densely populated area: lessons learned from the medical management of a terrorist attack. Prehospital and Disaster Medicine. 2007;22(3):186-192. doi:10.1017/S1049023X00004635.

[107] King DR, Larentzakis A, Ramly EP. Tourniquet use at the Boston Marathon bombing. Journal of Trauma and Acute Care Surgery. 2015;78(3):594-599. doi:10.1097/ta.0000000000000561.

[108] Miller L. Psychological interventions for terroristic trauma: Symptoms, syndromes, and treatment strategies. Psychotherapy. 2003;39(4):283-296. doi:10.1037/0033-3204.39.4.283.

[109] Miller L. On-scene crisis intervention: Psychological guidelines and communication strategies for first responders. International Journal of Emergency Mental Health. 2010;12(1):11-19.

[110] Gómez A, Domínguez C, Pedrueza C, Calvente R, Lillo V, Canas $\mathrm{J}$. Management and analysis of out-of-hospital health-related responses to simultaneous railway explosions in Madrid, Spain. European Journal of Emergency Medicine. 2007;14(5):247-255. doi:10.1097/mej.0b013e3280bef7c2.

[111] Leiba A, Blumenfeld A, Hourvitz A, Weiss G, Peres M, Schwartz D et al. A four-step approach for establishment of a national medical response to mega-terrorism. Prehospital and Disaster Medicine. 2006;21(6):436-440. doi:10.1017/S1049023X00004167.

[112] Assa A, Landau DA, Barenboim E, Goldstein L. Role of Air- Medical Evacuation in Mass- Casualty Incidents-A train collision experience. Prehospital and Disaster Medicine. 2009;24(3):271-276. doi:10.1017/S1049023X00006920.

[113] Pinkert M, Leiba A, Zaltsman E, Erez O, Blumenfeld A, Avinoam S, 
et al. The significance of a small, level-3 'semi evacuation' hospital in a terrorist attack in a nearby town. Disasters. 2007;31(3):227-235. doi:10.1111/j.1467-7717.2007.01006.x.

[114] Vidali A, Hutchens J. In: Kamien D, editor. Pervasive readiness: pipedream or possible?. 2nd ed. New York, NY, USA: McGraw-Hill;
2012. pp. 367-396.

[115] Peleg K. The Danger of Complacency - Readiness and Preparedness $=$ Effective Outcomes. Annals of Surgery. 2014;260(6):967968. doi:10.1097/sla.0000000000000987. 